\title{
Characterization of Embedded Sensors in Stainless Steel Test Articles and Design/Planning for MAGNET Testing
}

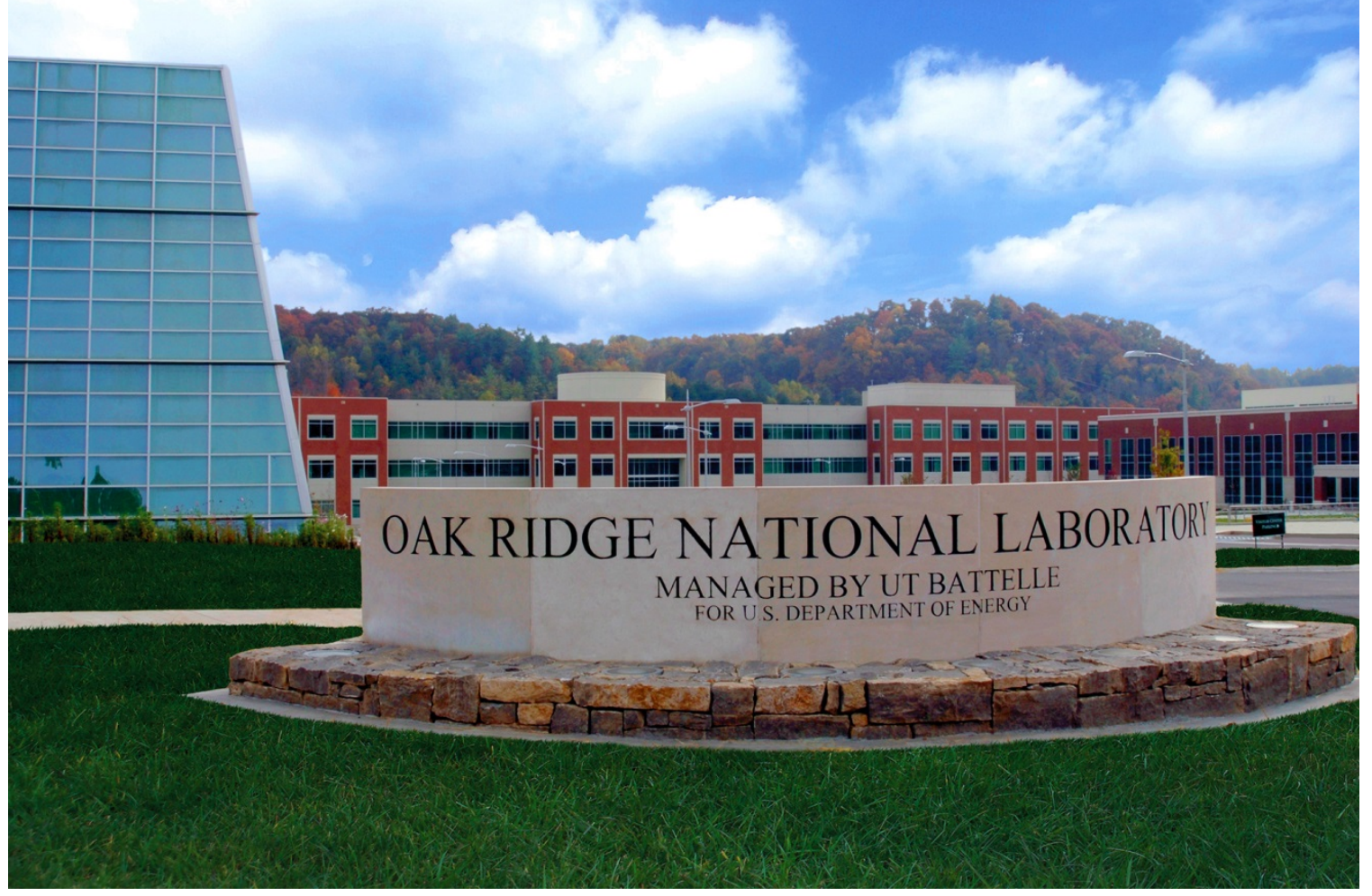

Holden C. Hyer

Daniel C. Sweeney

Christian M. Petrie

July 2021

Approved for public release. Distribution is unlimited. 


\section{DOCUMENT AVAILABILITY}

Reports produced after January 1, 1996, are generally available free via US Department of Energy (DOE) SciTech Connect.

Website www.osti.gov

Reports produced before January 1, 1996, may be purchased by members of the public from the following source:

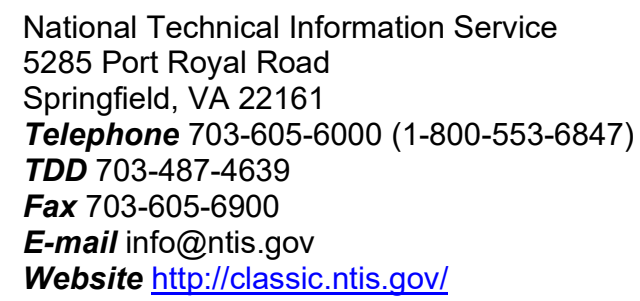

Reports are available to DOE employees, DOE contractors, Energy Technology Data Exchange representatives, and International Nuclear Information System representatives from the following source:

Office of Scientific and Technical Information

PO Box 62

Oak Ridge, TN 37831

Telephone 865-576-8401

Fax 865-576-5728

E-mail reports@osti.gov

Website http://www.osti.gov/contact.html

This report was prepared as an account of work sponsored by an agency of the United States Government. Neither the United States Government nor any agency thereof, nor any of their employees, makes any warranty, express or implied, or assumes any legal liability or responsibility for the accuracy, completeness, or usefulness of any information, apparatus, product, or process disclosed, or represents that its use would not infringe privately owned rights. Reference herein to any specific commercial product, process, or service by trade name, trademark, manufacturer, or otherwise, does not necessarily constitute or imply its endorsement, recommendation, or favoring by the United States Government or any agency thereof. The views and opinions of authors expressed herein do not necessarily state or reflect those of the United States Government or any agency thereof. 
Nuclear Energy and Fuel Cycle Division

\title{
CHARACTERIZATION OF EMBEDDED SENSORS IN STAINLESS STEEL TEST ARTICLES AND DESIGN/PLANNING FOR MAGNET TESTING
}

\author{
Holden C. Hyer \\ Daniel C. Sweeney \\ Christian M. Petrie
}

July 2021

Milestone \#: M3AT-21OR0804051

Prepared by

OAK RIDGE NATIONAL LABORATORY

Oak Ridge, TN 37831-6283

managed by

UT-BATTELLE LLC

for the

US DEPARTMENT OF ENERGY

under contract DE-AC05-00OR22725 



\section{TABLE OF CONTENTS}

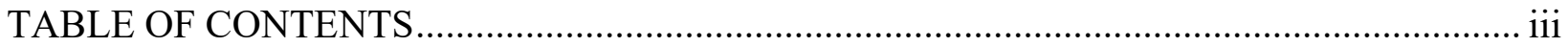

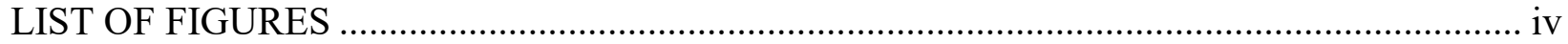

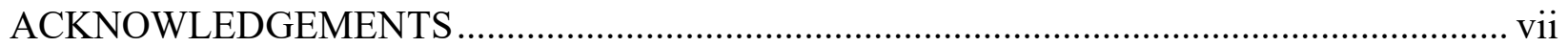

LIST OF ACRONYMS AND ABBREVIATIONS ……....................................................... viii

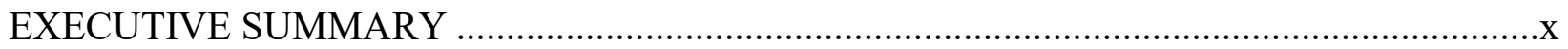

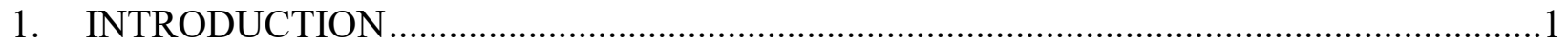

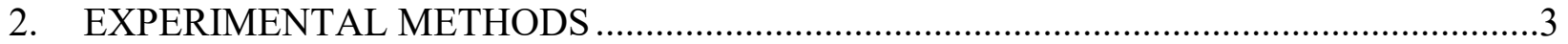

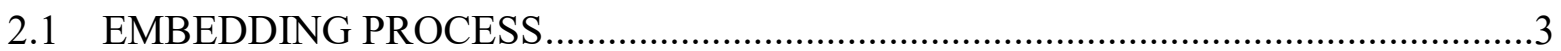

2.2 TEST ARTICLE DESIGN AND SENSOR DETAILS ……......................................

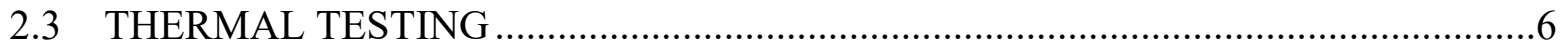

2.4 HARDNESS AND MICROSTRUCTURAL CHARACTERIZATION ………..............6

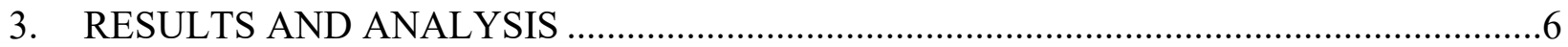

3.1 NON-DESTRUCTIVE INTERROGATION OF EMBEDDED FIBERS ......................6

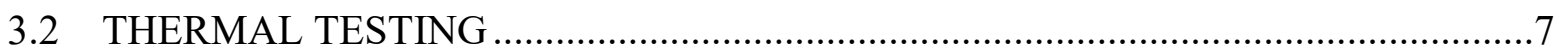

3.2.1 Transient Heating with a Moving Heat Source .................................................

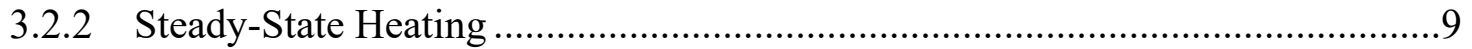

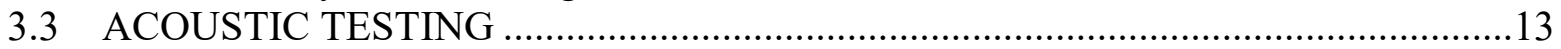

3.4 EFFECTS OF UAM PROCESSING ON MICROSTRUCTURE AND

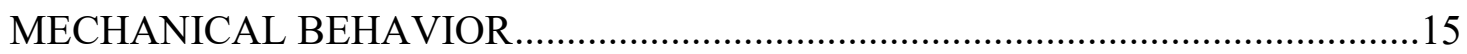

3.4.1 Microstructural Characterization.............................................................15

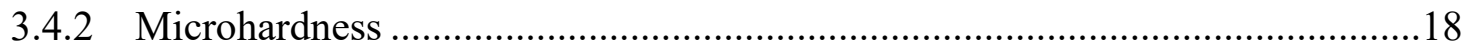

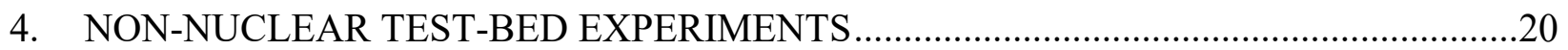

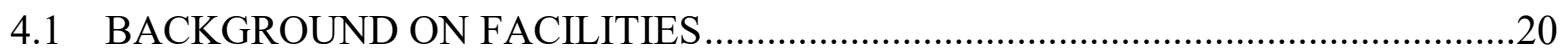

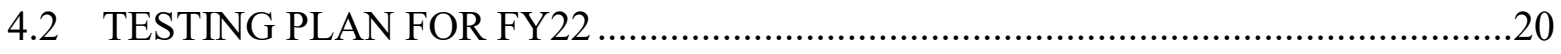

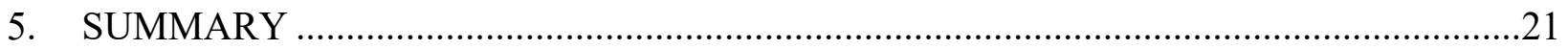

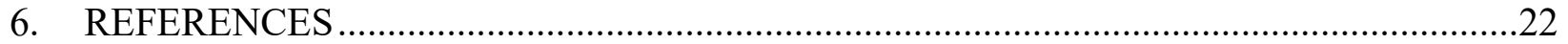




\section{LIST OF FIGURES}

Figure 1. Schematic of a heat pipe-based reactor and the general flow of the working fluid inside the sheath of a heat pipe.

Figure 2. Schematic representations of the (a) UAM process and (b) fiber embedding process, including (1) machining a channel in the base plate, (2) laying the coated fiber optic in the channel, and (3) layering additional foils on top, embedding the sensor.

Figure 3. CAD model of the SS304 pipe test article showing the location of the (a) embedded thermocouples, (b) the embedded fiber optic strain sensors, and (c) the finished part...

Figure 4. CAD model of the SS304 hex block test article showing an (a) isometric view of the final design and (b) top-down views of the thermocouple channels and (c) fiber optic channels.

Figure 5. Reflected fiber-optic signal amplitude and residual strain vs. spatial position along the embedded fiber in the (a) pipe and (b) hex block test articles.

Figure 6. Strain maps vs. time measured using the (a) embedded and (b) floating fibers during transient thermal testing. Measured strains from the embedded and floating fibers compared with the temperatures and calculated thermal strains using the embedded thermocouples (c) TC1 and (d) TC2. The approximate locations of the thermocouples TC1 and TC2 relative to the fiber optics are indicated by the dashed lines in (a).

Figure 7. (a) Photo of the steady-state thermal heating test showing set-up and locations of thermocouples used to monitor temperatures. Temperature data read from the thermocouples placed on the (b) cold and (c) hot sides.

Figure 8. (a) Strain measured from the embedded fiber mapped spatially along the length of the embedded region during the entire thermal testing. (b) Expected strain from the changes in thermal expansion between the $\mathrm{SS} 304$ matrix and $\mathrm{SiO}_{2}$ fiber compared with the measured strain from the embedded fiber, the floating fiber, and their difference. (c) Comparison of temperature measurements between the embedded thermocouples, the floating fiber, and the embedded fiber, assuming that the fiber is no longer embedded with the SS304 matrix. The fiber data are plotted at the location of TC1.

Figure 9. Steady-state thermal analysis of the pipe, showing the (a) temperature profile, (b) normal strain of the pipe, and (c) normal strain in the fiber. The model shows only $1 / 4$ of the pipe due to symmetry. The free end of the pipe is shown on the right side of each image.

Figure 10. ( $a, b)$ Results of acoustic testing after tapping a pipe with a hammer (a) directly on the embedded region of the pipe and (b) on the work bench as well as the pipe. In (b), 10 raps were performed on the work bench away from the pipe, then on the work bench near pipe, and finally directly on the pipe with a few second delay in between each set of raps. Moreover, only the raps directly on the pipe were observed. Intensities in power density were observed near 5,000 and 10,000 Hz. (c, d) ANSYS finite element modeling showing the vibrational modes at two different identified resonant frequencies: (c) 5,098 and (d) $10,076 \mathrm{~Hz}$

Figure 11. Backscatter electron micrographs of the cross-sections of embedded fibers with (a) successful and (b) unsuccessful bonding of the fiber to matrix.

Figure 12. Backscatter electron micrographs of (a) the region between the bulk and the SS304 foils, (b) high magnification of the UAM'ed SS304 foils, and (c, d) high magnification of the grain structure of the $\mathrm{Ni}$ inter-layer at the interface of the $\mathrm{SS} 304$ foils.

Figure 13. EDSD grain mapping of the (a) bulk region and (b) interface between two UAM foils. The dashed line in (b) indicates the boundary of the Ni inter-layer. The build direction of the samples is given with respect to the bottom length of the images. 
Figure 14. (a, c, e) Vickers hardness data for the areas indicated in (b, d, f), respectively. Indentation was performed on the sample with good bonding to the SS304 matrix. 


\section{ACKNOWLEDGEMENTS}

This work is supported by the Microreactor Program of the US Department of Energy's (DOE)'s Office of Nuclear Energy. Embedded fiber-optic sensor fabrication and testing was originally sponsored by the Laboratory Directed Research and Development program of Oak Ridge National Laboratory (ORNL), which is managed by UT-Battelle LLC for DOE. Dan King, Adam Hehr, and Mark Norfolk of Fabrisonic LLC performed the sensor embedding. Holly Trellue of Los Alamos National Laboratory provided the 3D printed hex block for sensor embedding. In the Metallography laboratory at ORNL, Victoria Cox helped with the sample metallography preparation for microscopy and the Vickers hardness mechanical indentation. 


\section{LIST OF ACRONYMS AND ABBREVIATIONS}

$\begin{array}{ll}\text { AM } & \text { additive manufacturing } \\ \text { DIC } & \text { digital image correlation } \\ \text { DOE } & \text { US Department of Energy } \\ \text { EBSD } & \text { electron backscatter diffraction } \\ \text { EDS } & \text { x-ray energy dispersive spectroscopy } \\ \text { INL } & \text { Idaho National Laboratory } \\ \text { LANL } & \text { Los Alamos National Laboratory } \\ \text { MAGNET } & \text { Microreactor Agile Non-Nuclear Testbed } \\ \text { OBR } & \text { optical backscatter reflectometry } \\ \text { ORNL } & \text { Oak Ridge National Laboratory } \\ \text { SEM } & \text { scanning electron microscope } \\ \text { SPHERE } & \text { Single Primary Heat Extraction and Removal Emulator } \\ \text { SS } & \text { stainless steel } \\ \text { UAM } & \text { ultrasonic additive manufacturing } \\ \text { VHN } & \text { Vickers hardness number }\end{array}$




\section{EXECUTIVE SUMMARY}

The nuclear industry is pursuing microreactors that can be factory assembled and deployed to remote regions for reliable power generation. One class of microreactors uses a monolithic metal core block coupled to heat pipes for heat rejection, which results in significant thermal stresses in the monolithic structures. This work describes the initial characterization and test plan for evaluating stainless steel test articles fabricated with embedded sensors for measuring heat pipe performance limits, as well as spatially distributed temperatures and strains during electrically heated thermal testing. The electrically heated testing will be performed in the non-nuclear Microreactor Agile Non-Nuclear Testbed and Single Primary Heat Extraction and Removal Emulator facilities located at Idaho National Laboratory. The goals of these tests are to (1) accurately monitor temperature and strain distributions that result from differential thermal expansion in the test articles and (2) quantify heat rejection limits of heat pipes as a function of operating temperature and working fluid during steady-state and transient operations. More generally, the ability to monitor component and system health during microreactor operation is attractive for providing a high sensor density to inform a limited number of microreactor operators to ultimately reduce operation and maintenance costs and move toward semi-autonomous operation.

This report discusses the characterization of embedded thermocouples and fiber optic sensors in relevant test articles, including cylindrical pipes and hexagonal monolithic test articles for heat pipe-based reactors. The sensors were embedded by placing them in machined channels and then building up additional material by using ultrasonic additive manufacturing (UAM). UAM is a solid-state welding process that uses downward pressure and a lateral scrubbing motion to bond thin metal foils to a base material layer by layer. The ultrasonic welding process relies on the plastic deformation of the metal-as opposed to typical melting and solidification - to break oxide scales and bond the metal layers. The characterization of these embedded sensors included evaluating fiber optic signal attenuation, observing residual strain in the fibers, investigating microstructural and mechanical aspects, and demonstrating the sensors under various thermal loads and acoustic vibrations. Post-embedding characterization showed a fine grain structure $(<1 \mu \mathrm{m})$ near the interfaces of the bonded foils as a result of severe deformation from the welding process. A large increase in hardness was observed at the foil interfaces and the fiber/matrix interface compared with the bulk matrix. Even when compared with the SS304 interfaces, the higher hardness observed around the embedded fiber suggests a higher degree of deformation due to the soft metal coating around the silica fiber core. The distributed fiber-optic temperature sensors and embedded thermocouples reliably measured temperature distributions during steady-state and transient thermal testing. The embedded fiber-optic sensors reliably measured strain during both transient and steady-state testing and properly identified resonant frequencies during acoustic testing. 


\section{INTRODUCTION}

The ability to deploy microreactors with a modular design, factory assembly, reduced construction costs, and enhanced passive safety is highly attractive for applications that require deployable energy on the order of kilowatts to tens of megawatts, particularly in remote areas [1-3]. Some microreactor concepts are being designed with passive safety features and higher operating temperatures to improve thermal efficiencies. Although some water-cooled microreactor concepts are being considered, most concepts generally use flowing He, molten salt, or liquid metal coolants. However, an additional class of microreactors takes advantage of the passive heat removal capabilities of heat pipes, which leverage boiling and condensation processes to transport heat from the core to a heat sink that can be placed far away from the core and eliminate the need for forced circulation within the core [3].

Heat pipes are closed-ended cylinders filled with a high vapor pressure metal, such as Na or K [3-5]. As the metal vaporizes at the hot end (i.e., fueled region), the vapor circulates to the cold end (i.e., heat sink) and then flows back toward the hot end via capillary action in a porous wick structure on the inner surface of the heat pipe, as shown in Figure 1. A properly designed heat pipe operates under near isothermal conditions. However, there is limit to how much heat or heat flux can be rejected from a heat pipe, depending on the working fluid and the operating temperature [5]. These thermal limits are based on (1) sonic velocity limits at the evaporator exit, (2) capillary flow limitations in the wick, (3) entrainment counter-flow limits, and (4) boiling and local dryout near the wall [6]. In addition to understanding heat rejection limits, heat pipe-based microreactors also generate significant thermal stresses in the monolithic metal core blocks that transfer heat from the fuel to the heat pipes. If these stresses become too high, then the heat pipe could de-bond from the core block, which would further increase the heat that must be rejected to the surrounding heat pipes. The de-bonding of a heat pipe or otherwise exceeding the heat rejection limits of a single heat pipe could initiate a cascading failure after the surrounding heat pipes are forced to reject a larger heat load. Therefore, it is necessary to understand the fundamental heat rejection limitations of heat pipes as a function of operating temperature and working fluid, as well as the thermal stresses that are generated in the core block during reactor operation. This requires detailed mappings of temperature and strain within heat pipes and their surrounding test articles during representative internal heating at temperatures that range from 500 to $>900^{\circ} \mathrm{C}$. 


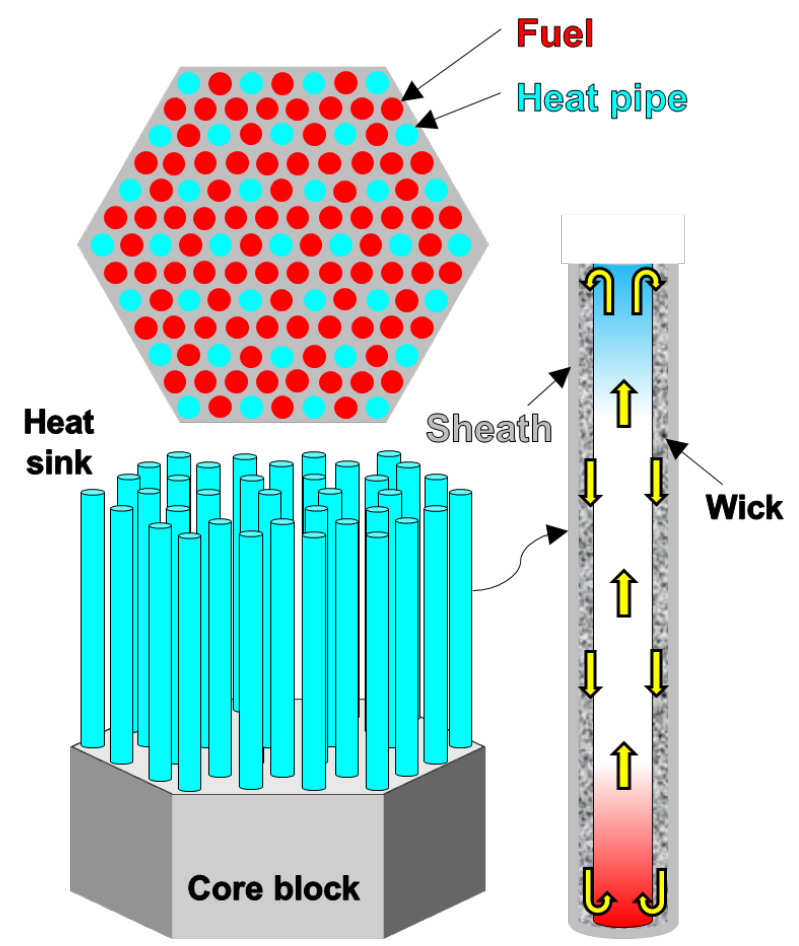

Figure 1. Schematic of a heat pipe-based reactor and the general flow of the working fluid inside the sheath of a heat pipe.

Fiber optic sensors are a promising technology for measuring temperature and strain distributions due to their ability to operate at high temperatures $\left(>1,000^{\circ} \mathrm{C}\right)$ [7-10] and moderate radiation dose [9-11]. Furthermore, temperature and strain can both be continually measured along the length of the entire fiber $[7,12]$. However, for accurate strain measurements, the fiber must have adequate mechanical coupling with the component. Ideally the fiber-optic sensors could be directly embedded and bonded within the surrounding metal matrix [12-17], thus eliminating concerns related to the degradation of adhesives at high temperatures or under irradiation. Typically, 316L and 304 stainless steels (SSs) are chosen for the core block materials because of their relatively high strength, corrosion resistance, and high commercial availability $[18,19]$. However, conventional SS processing via casting and subsequent working is not ideal for embedding fragile fiber optics. Therefore, recent studies have looked to additive manufacturing (AM) to rapidly prototype new component designs with geometric complexities $[20,21]$ and embed fiber optic sensors during the fabrication process $[12,15,16,22,23]$.

This report briefly describes recent advances in ultrasonic AM (UAM) to embed sensors in relevant microreactor test articles for improved health monitoring, as well as the initial characterization of embedded sensors within SS pipes and a miniature hexagonal test article representing a fraction of a microreactor core block. The test articles were designed for testing at the Microreactor Agile Non-Nuclear Testbed (MAGNET) and Single Primary Heat Extraction and Removal Emulator (SPHERE) facilities at Idaho National Laboratory (INL) [3, 24]. MAGNET and SPHERE are non-nuclear testbeds with electrical heaters used to simulate nuclear heating and the resulting temperature gradients that would be observed in microreactors [1-3]. For this report, simplified thermal loads were applied to test articles with embedded temperature and strain sensors to evaluate their response to both steady-state and transient temperature changes before MAGNET and SPHERE tests. Additionally, detailed microstructural analysis and mechanical indentation were performed to examine the interfaces between the embedded sensors and the surrounding metal matrix. 


\section{EXPERIMENTAL METHODS}

\subsection{EMBEDDING PROCESS}

The most common metal AM processes include powder bed fusion (PBF) and direct metal deposition methods, which both involve localized melting to produce metallic components with complex geometries and near net shape [20,25]. However, embedding sensors via these processes is challenging because the sensors can be easily damaged during melting or from residual stress caused by the high cooling rates observed with these methods [26,27]. This is especially true when embedding fragile sensors such as fiber optic sensors [27, 28]. As shown in Figure 2(a), UAM is a solid-state fusion process in which thin metal foils are welded together through a combination of applied force and ultrasonic vibration $[29,30]$. Since no melting occurs in UAM, the process relies on severe plastic deformation to break the surface oxide scales and metallurgically bond the two metals [31,32].

$\mathrm{Al}$ and $\mathrm{Cu}$ alloys have been widely investigated by UAM due to their relatively low strength and soft/ductile nature [16, 31-36]. Typically, UAM is designed to be a hybrid process, where the fusion technique is coupled with a computer numerical control system, allowing for the combination of additive and subtractive manufacturing. This pairing has allowed for novel component development such as fabricating complicated heat sinks or cooling systems [29, 37]. More importantly, the low temperature nature of this process is ideal for embedding fragile sensors in a metal matrix (Figure 2(b)) [15, 16, 30, 33]. As Petrie et al. [16] have demonstrated in $\mathrm{Al}$ and $\mathrm{Cu}$, fiber optic sensors have been embedded in metal matrices, with successful measurements of temperature and strain during post-build thermal testing. However, the UAM process required development to be extended to more relevant microreactor materials, such as face-centered cubic (FCC) austenitic SS316 and SS304, and geometries (round pipes and hexagonal blocks). Due to the high hardness of the SS304 foils and baseplate, the foils often bond to the weld head (or sonotrode) instead of the baseplate. To prevent this, a Stellite-coated titanium sonotrode was used to minimize wear of the weld head and maximize bonding of the foils to the base. In addition, the $\sim 0.006-0.007$ in thick SS304 foils were plated with a thin $(<0.001$ in) pure Ni coating to improve foil bonding. The UAM parameters used for welding/embedding included a downward force of $7 \mathrm{kN}$, scrubbing amplitude of 31.5-33.5 $\mu \mathrm{m}$, weld head traverse speed of $50 \mathrm{in} \cdot \mathrm{min}^{-1}$, and an ultrasonic frequency of $20 \mathrm{kHz}$. 


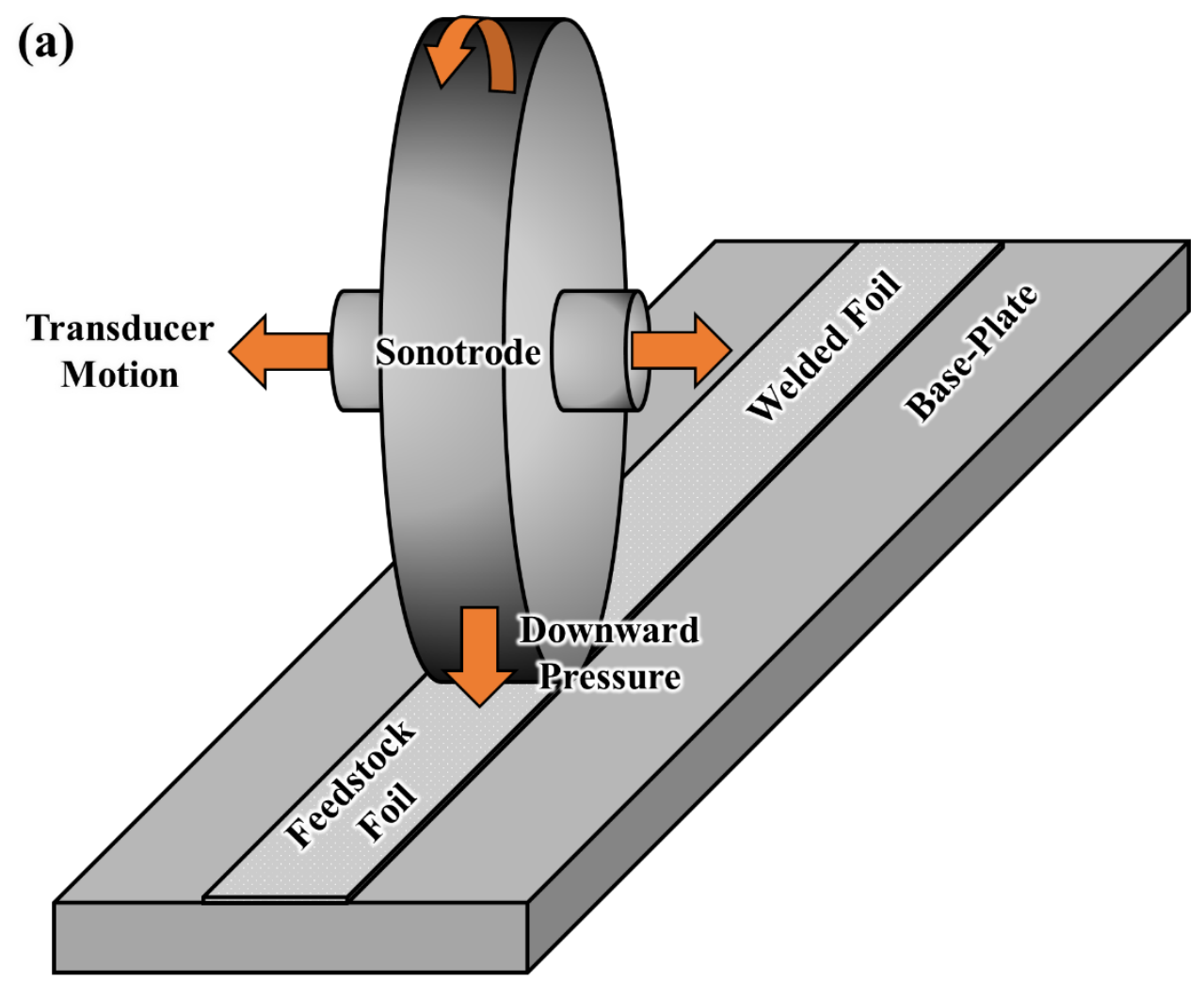

(b)

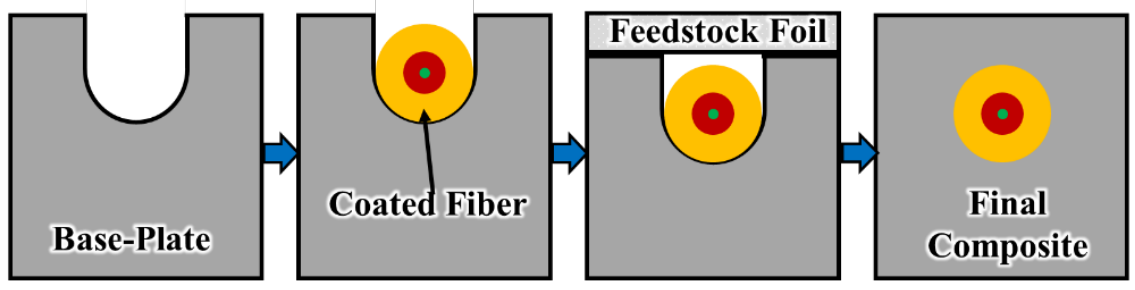

Figure 2. Schematic representations of the (a) UAM process and (b) fiber embedding process, including (1) machining a channel in the base plate, (2) laying the coated fiber optic in the channel, and (3) layering additional foils on top, embedding the sensor.

\subsection{TEST ARTICLE DESIGN AND SENSOR DETAILS}

Because UAM generally requires a flat surface to ensure good bonding, the process has historically been used primarily for simple plate-like geometries. Therefore, changes in fixturing were required to embed sensors within the pipes and seven-hole test articles, as described in more detail previously [24]. The testing described in this work was performed on one of the pipe specimens (Figure 3), with a 3 in (76 $\mathrm{mm}$ ) outer diameter, and $3 / 8$ in $(9.5 \mathrm{~mm})$ wall thickness. The seven-hole hex block (Figure 4$)$ will be used for testing in SPHERE or MAGNET. As described previously [24], the embedded sensors included Type $\mathrm{K}$ thermocouples and $\mathrm{Cu}-\mathrm{Ni}$ coated Ge-doped fused silica optical fibers. These fibers were chosen due to their high temperature resistance. Metal coatings are favored over more polymer-based coatings, particularly for strain sensing at temperatures beyond the combustion temperature of the polymer-based 
coatings. The channel widths for the fiber optic strain sensors were machined with a 0.008 in end mill to a total depth of 0.0125-0.013 in As shown in Figure 4(b), additional larger channels were machined and left empty for the insertion of a "floating" fiber after the UAM procedure to compare the performance of an embedded vs. floating fiber.

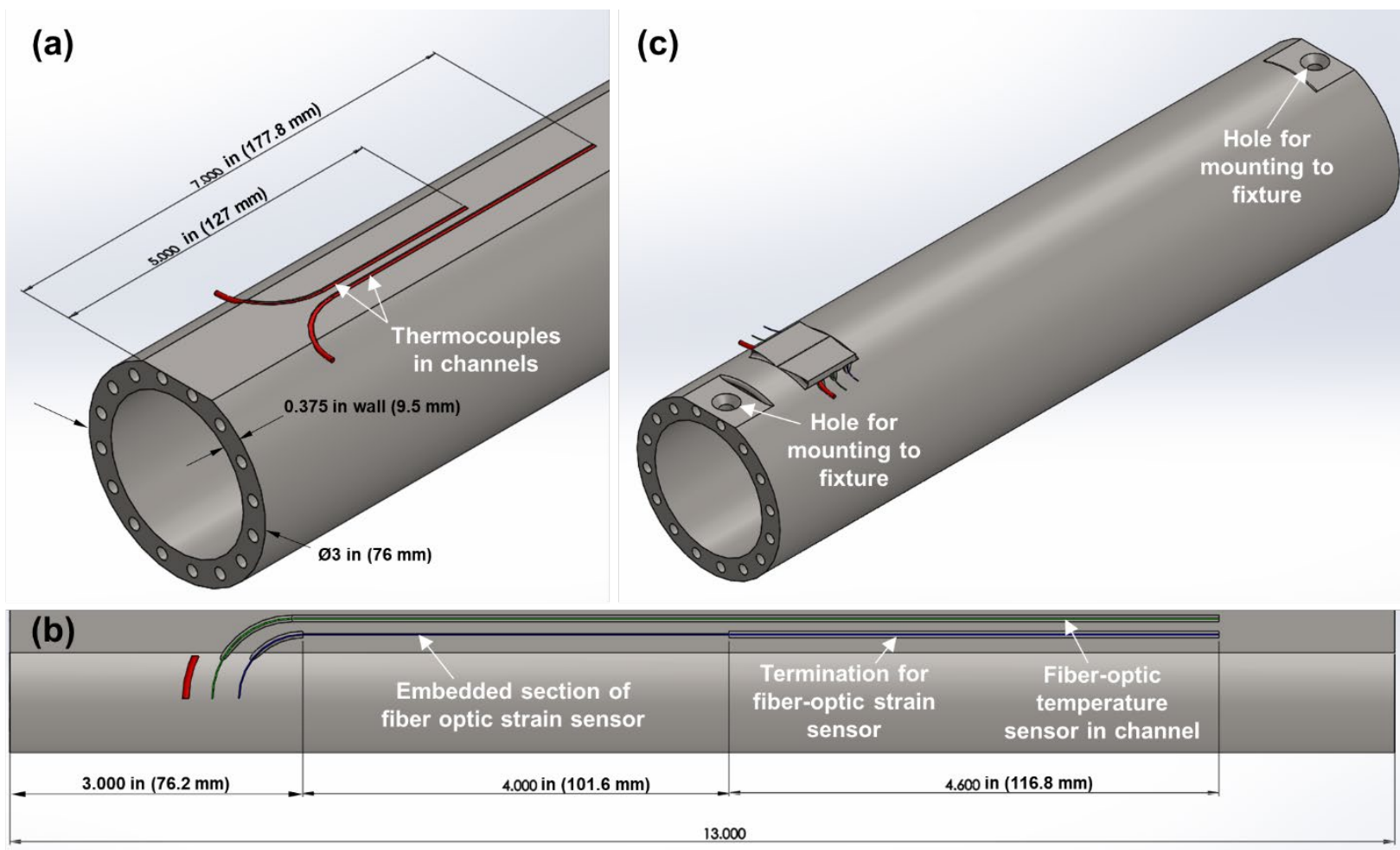

Figure 3. CAD model of the SS304 pipe test article showing the location of the (a) embedded thermocouples, (b) the embedded fiber optic strain sensors, and (c) the finished part.

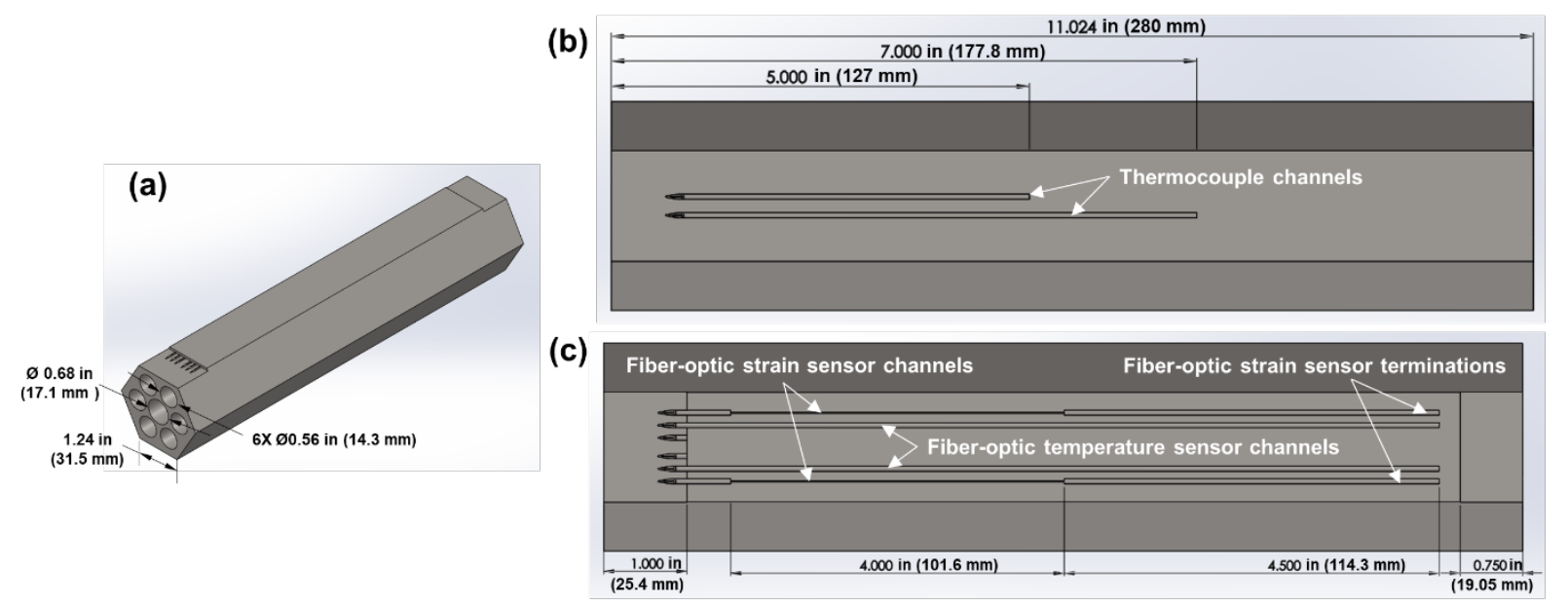

Figure 4. CAD model of the SS304 hex block test article showing an (a) isometric view of the final design and (b) top-down views of the thermocouple channels and (c) fiber optic channels. 


\subsection{THERMAL TESTING}

A pipe with embedded sensors was subjected to multiple thermal tests to induce steady-state and transient thermal gradients to ensure that the embedded sensors perform as expected before testing in MAGNET or SPHERE. The transient test was performed by passing a heat gun (Master Heat Gun, 1,680 W output power) along the length of the pipe, maintaining a distance of $\sim 1$ in between the heat gun and the outer surface of the pipe. The test was conducted for $5 \mathrm{~min}$, achieving a maximum temperature of $\sim 100^{\circ} \mathrm{C}$. Steady-state testing was performed by cooling the embedded region with flowing chilled water while the opposite side of the pipe was heated with a heat tape strip. The cooling was provided by clamping $1 / 4$ in. diameter $\mathrm{Cu}$ tubing along the embedded region of the pipe and flowing chilled water through the tubing. The steady-state testing was performed over $4 \mathrm{~h}$ to ensure that a thermal equilibrium was achieved.

During testing, the fibers were interrogated by using optical backscatter reflectometry (OBR), which relies on Raleigh backscattering along the length of the silica fibers to measure distributed strain and temperature. Each fiber was terminated with a 4 in termination fiber that prevents large reflections from the end of the fiber from interfering with sensing measurements near the end of the fiber. The interrogator used for this study was an ODiSI 6108 (Luna Innovations), which collected data at 10-50 Hz. More information on OBR and Raleigh backscattering can be found in other works $[15,38]$. The thermocouples were connected to a data logger (Squirrel, Grant Instruments) that was armed at the same time that the fibers were interrogated by the OBR instrument.

\subsection{HARDNESS AND MICROSTRUCTURAL CHARACTERIZATION}

Two additional samples with embedded $\mathrm{Cu}$-Ni-coated fibers were fabricated by using flat SS304 plates to allow for microstructural and mechanical characterization of the fiber and/or matrix interface. All channel dimensions and UAM process parameters were similar to those used for the pipe and seven-hole hex block test articles. After the embedding process, the plates were cross-sectioned, cold mounted in epoxy, and polished to a final finish of $0.05 \mu \mathrm{m}$ with colloidal silica. The samples were then analyzed with a field-emission scanning electron microscope (SEM) (Tescan Mira3) operated at $20 \mathrm{kV}$. Based on previous observations of fine grains $(<1 \mu \mathrm{m})$ along the layer-layer interfaces caused by severe plastic deformation during UAM, electron backscatter diffraction (EBSD) was performed on the samples with step sizes of 1 and $0.1 \mu \mathrm{m}$ for the low and high magnification scans, respectively.

After SEM analysis, the polished samples were subjected to Vickers hardness micro-indentation. Three arrays of 200 indents each were performed across the UAM layers and the embedded fiber. Because of the high degree of plastic deformation expected from the UAM process, Vickers hardness was chosen to evaluate any differences at the layer-layer and layer-fiber interfaces.

\section{RESULTS AND ANALYSIS}

\subsection{NON-DESTRUCTIVE INTERROGATION OF EMBEDDED FIBERS}

Successfully embedding fiber-optic strain sensors can nondestructively evaluate the amplitude of the reflected signal along the length of the embedded region and the residual strain in the fiber, which indicates some mechanical coupling. This is accomplished by interrogating the fiber before and after embedding via OBR. The reflected signal amplitude can be determined as a function of position by using a Fourier transform [39] with the beat frequencies of the observed interference pattern being proportional to the distance from the OBR instrument. Residual strain can be calculated by windowing over select spatial regions, transforming the data back into the optical frequency domain, and performing a cross 
correlation of the pre- and post-embedding scans [16]. This is used to calculate local spectral shifts, which can be converted to mechanical strain. Figure 5 shows the spatial residual strain $\left(\mu \mathrm{m}^{\cdot} \mathrm{m}^{-1}\right)$ as a function of position along the fiber, as well as the post-embedding reflected signal amplitude. The residual strains are approximately $2,000-2,500 \mu \mathrm{m} \cdot \mathrm{m}^{-1}$ for the pipe test article, which is consistent with what was observed in previous works on embedding fiber optics in metals [15]. The strain in both test articles is compressive, which implies that successful strain bonding has occurred. Moreover, the observed strain occurs over a length of $\sim 100 \mathrm{~mm}$, which is consistent with the length of the embedded region of the fiber, as is shown in Figure 3 and Figure 4. Finally, the amplitudes are constant throughout the scan, which suggests that there are minimal signal losses that result from the embedding process.
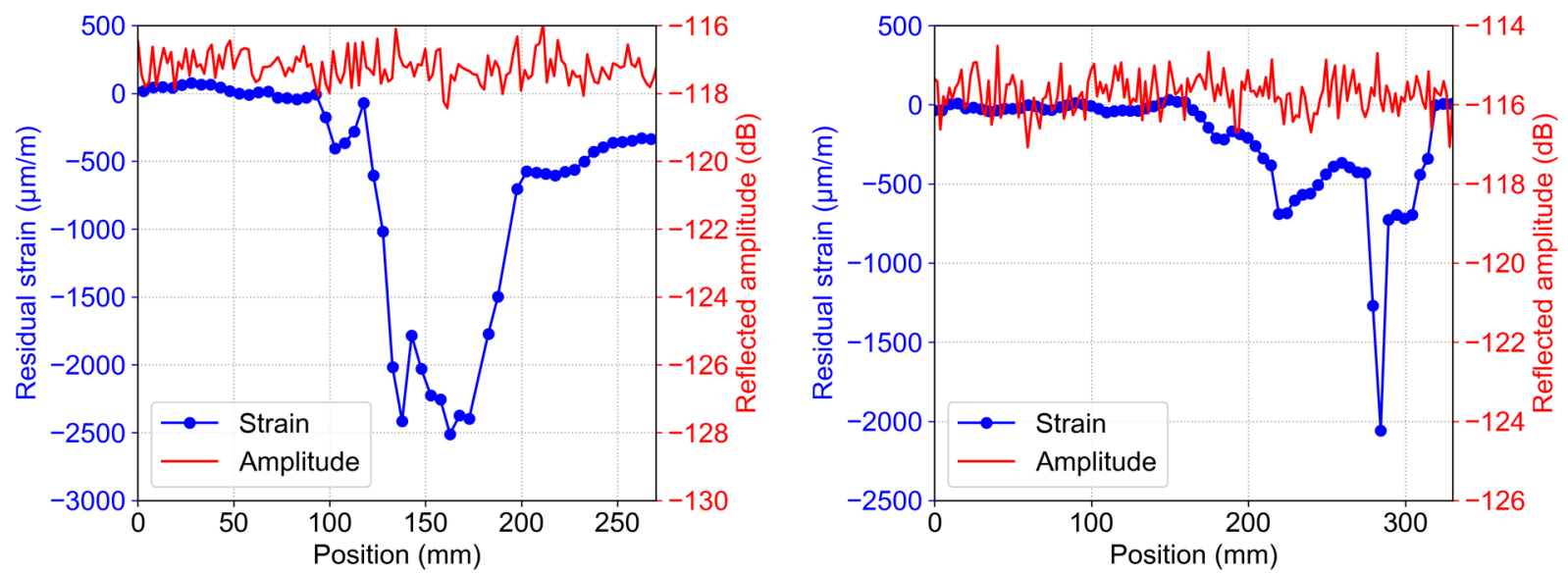

Figure 5. Reflected fiber-optic signal amplitude and residual strain vs. spatial position along the embedded fiber in the (a) pipe and (b) hex block test articles.

\subsection{THERMAL TESTING}

With confidence that the fiber optic strain sensors were properly embedded, the next step was to perform initial thermal testing before testing in SPHERE or MAGNET. If the fiber is properly embedded, it will be coupled with the SS304 matrix and measure a change in strain at higher temperatures due to the differences in thermal expansion between the fiber and SS304 matrix. However, the strain is determined from local spectral shifts in the OBR interference pattern, and the spectral shifts are also affected by changes in temperature due to thermo-optic effects and thermal expansion of the fiber itself that are unrelated to differential thermal strains between the fiber and the matrix. Therefore, for all thermal tests, a "floating" fiber was placed inside the open channels indicated in Figure 3(b). The floating fiber has no mechanical coupling to the part and acts as a temperature-only sensor that can be used to compensate for the portion of the "strain" measured by the embedded fiber that is only caused by changes in temperature. To perform this compensation, the strain from the floating fiber can be subtracted from the strain measured in the embedded fiber to give the true strain in the embedded fiber.

\subsubsection{Transient Heating with a Moving Heat Source}

The first thermal test involved passing a heat gun over the surface of the embedded region. The heat gun was held $\sim 1$ in away from the embedded region and moved axially back and forth across the embedded region in $30 \mathrm{~s}$ intervals, pausing for $\sim 2 \mathrm{~s}$ at each end of the embedded region. Figure 6 summarizes the measured strains and temperatures during these tests. In Figure 6(a), the strains measured by the embedded fiber are mapped as a function of time and distance from the start of the embedded region. 
Zigzag patterns can be observed in the map, detailing the movement of the heat gun. In comparison, the strain mapping of the floating fiber is shown in Figure 6(b). No zigzag patterns were observed in the floating fiber strain data. Moreover, the magnitude of the strain is much lower compared with that in Figure 6(a) for the embedded fiber.

The theoretical differential expansion strain that would result in a fiber embedded in an infinitely thick SS304 matrix was calculated from the difference in thermal expansion, $\alpha$, between the silica fiber and SS304 matrix: $\left(\alpha_{\mathrm{SS} 304}(\mathrm{~T})-\alpha_{\mathrm{SiO} 2}(\mathrm{~T})\left(\mathrm{T}-\mathrm{T}_{0}\right)\right.$. The effects of the $\mathrm{Cu}$ coating were considered negligible because the coating thickness (tens of micrometers) is orders of magnitude thinner than the surrounding SS304 matrix $[15,16]$. The temperature data used for the calculation were taken from the two embedded thermocouples. The thermocouples were embedded near the end and middle of the embedded region, as per Figure 3, are henceforth labeled TC1 and TC2, respectively. The positioning of TC1 and TC2 relative to the embedded region of the fibers is shown by the dashed lines in Figure 6(a).

Figure 6 (c) and Figure 6(d) show measured and calculated strains vs. time at the positions near TC1 and TC2, respectively. Overall, the measured strain in the floating fiber remained relatively low but increased over time. The data from the embedded fiber have a nature similar to that of the strain calculated from the thermocouple data. Data collected from the position near TC1 only shows five large distinct peaks, whereas the data collected near TC2 exhibits 10 smaller distinct peaks. Because the middle of the embedded region where TC2 is located sees the moving heat source twice, whereas the end of the embedded region only sees the heat source once for a prolonged period time, the peaks in strain data in Figure 6(c) and Figure 6(d) correlate well with the experimental design. Moreover, the magnitudes of the strain from the embedded fiber are similar to those calculated by thermal expansion. However, the two curves appear slightly off phase with each other, likely due to the difference in mass and response time between the fiber and the thermocouples. 

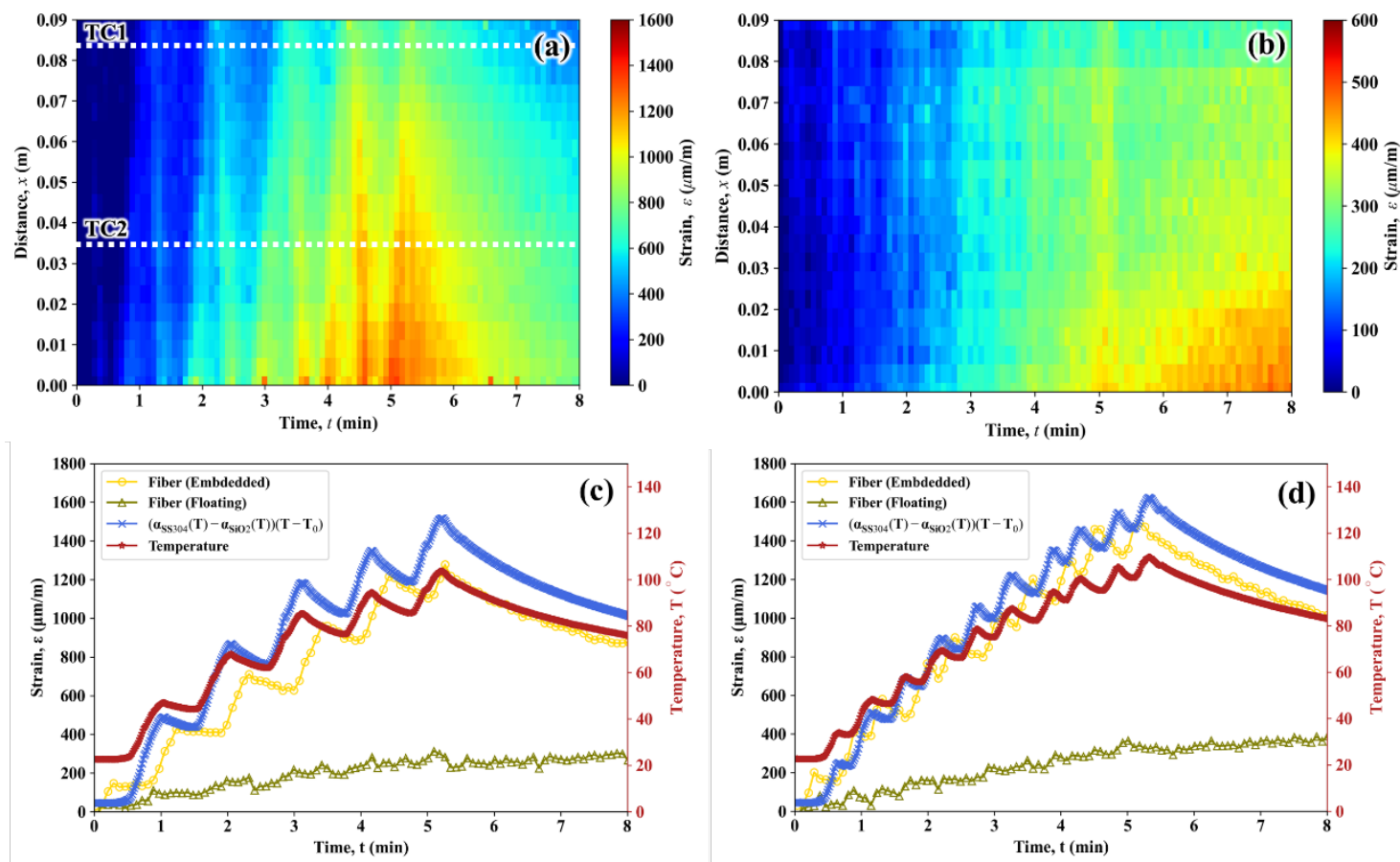

Figure 6. Strain maps vs. time measured using the (a) embedded and (b) floating fibers during transient thermal testing. Measured strains from the embedded and floating fibers compared with the temperatures and calculated thermal strains using the embedded thermocouples (c) TC1 and (d) TC2. The approximate locations of the thermocouples $\mathrm{TC} 1$ and $\mathrm{TC} 2$ relative to the fiber optics are indicated by the dashed lines in (a).

\subsubsection{Steady-State Heating}

Steady-state thermal testing was performed by creating a thermal gradient between a hot side heated by heat tape and a cold side, chilled with flowing water. The region with the embedded sensors was located on the cold side. Results from the steady-state testing are shown in Figure 7, Figure 8, and Figure 9. As shown in Figure 7(a), thermocouples were located at the water inlet and outlet to monitor the cooling temperature on the cold side. An additional thermocouple was placed between the heat tape and pipe as well as near the heat tape on the surface of the pipe on the hot side. The temperatures from these thermocouples are shown in Figure 7(b) for the cold side and Figure 7(c) for the hot side. Prior to powering the heat tape at time $\mathrm{t}=0$, the inlet and outlet cooling water temperatures were $\sim 15^{\circ} \mathrm{C}$. However, the coolant temperatures approached $40^{\circ} \mathrm{C}$ toward the end of the test as the test article temperatures increased (Figure 7(b)). The embedded thermocouples labeled TC1 and TC2 achieved maximum temperatures of approximately 61 and $54^{\circ} \mathrm{C}$, respectively. The maximum temperature of the heat tape reached $\sim 280^{\circ} \mathrm{C}$ (Figure $7(\mathrm{c})$ ), while the thermocouple located on the surface of the pipe's hot side, away from the heat tape, reached a maximum temperature of approximately $90^{\circ} \mathrm{C}$. Therefore, a gradient of approximately $30-35^{\circ} \mathrm{C}$ was observed across the pipe (from the hot to cold side). These gradients are comparable to those expected in heat pipe-based microreactor monoliths and during testing at both the MAGENT and SPHERE facilities. 

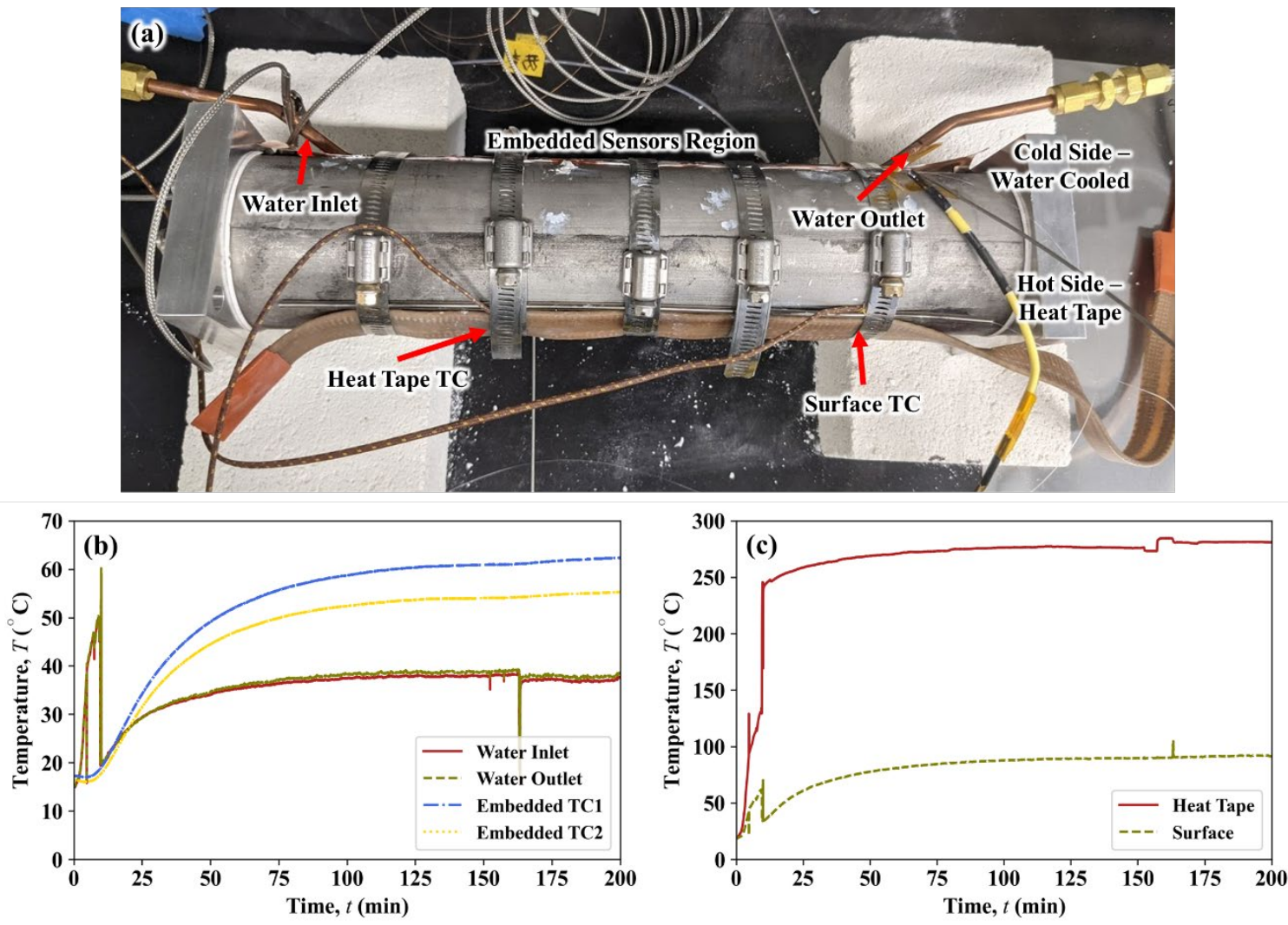

Figure 7. (a) Photo of the steady-state thermal heating test showing set-up and locations of thermocouples used to monitor temperatures. Temperature data read from the thermocouples placed on the (b) cold and (c) hot sides.

The measured strain from the embedded fiber on the cold side is shown in Figure 8(a) and is compared to the floating fiber in Figure 8(b). The magnitude of the strain in the embedded fiber is usually expected to be larger than that of the floating fiber, similar to what was observed in Figure 6, since the embedded fiber is affected by differential thermal strain in addition to temperature. However, the thermal stresses during steady state testing are different than those during transient testing, as shown later in this section. The floating and embedded fibers measured similar strains as shown in Figure 8(b). After subtracting the strain measured by the floating fiber from that measured by the embedded fiber, the resulting fiber strain has a maximum value of $\sim 50 \mu \mathrm{m} \cdot \mathrm{m}^{-1}$ ). While this might suggest that the fiber is no longer embedded, the compressive strain that was measured after the embedding process (Figure 5) and the large thermal strains that were measured during transient testing (Figure 6), suggest that the fiber was indeed embedded at some point. Moreover, the compressive strain measured by the embedded fiber at the start of the steady state testing when the temperature was $\sim 15^{\circ} \mathrm{C}$ (less than the reference temperature of $\sim 20^{\circ} \mathrm{C}$ ) was larger in magnitude compared to that measured using the floating fiber. This would also indicate that the fiber was embedded at the start of the steady state testing. Figure 8(c) shows temperatures measured by the embedded thermocouples TC1 and TC2 as well as the cold side floating fiber at a position near where TC1 is embedded. 

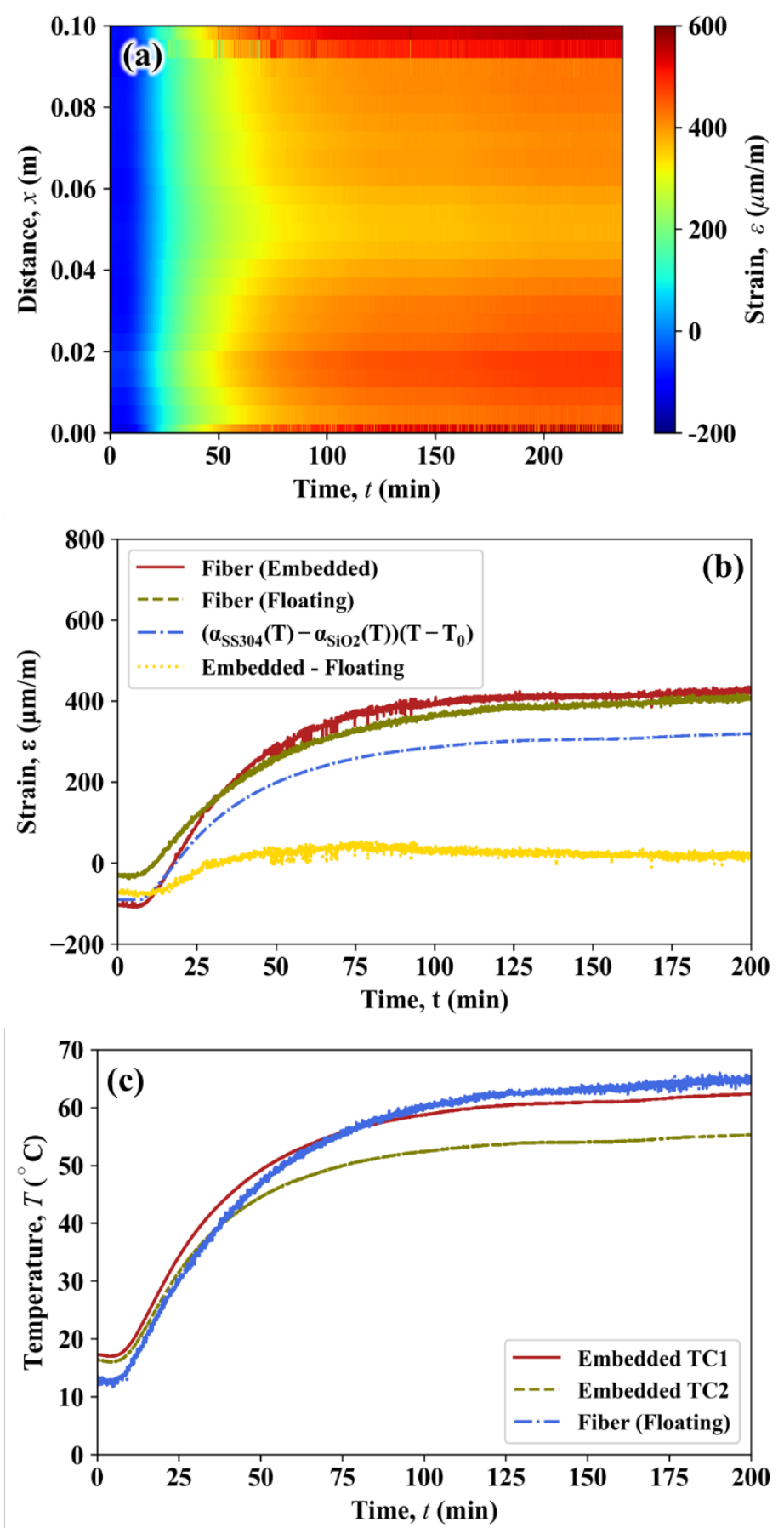

Figure 8. (a) Strain measured from the embedded fiber mapped spatially along the length of the embedded region during the entire thermal testing. (b) Expected strain from the changes in thermal expansion between the $\mathrm{SS}_{304}$ matrix and $\mathrm{SiO}_{2}$ fiber compared with the measured strain from the embedded fiber, the floating

fiber, and their difference. (c) Comparison of temperature measurements between the embedded thermocouples, the floating fiber, and the embedded fiber, assuming that the fiber is no longer embedded with the SS304 matrix. The fiber data are plotted at the location of TC1.

To understand the expected behavior of the embedded fiber during the steady-state testing, the experiment was modeled using the ANSYS finite element software. Steady-state modeling was performed on the pipe 
specimen with the dimensions as reported in Figure 3. A constant temperature boundary condition of $58^{\circ} \mathrm{C}$ was used on the cold side of the pipe to match the average thermal equilibrium temperature read by the embedded thermocouples. A constant heat flux was used to simulate the heat tape on the hot side. This heat flux was adjusted until the maximum simulated temperature matched that from the experiment. The maximum temperature achieved from the heat tape was $\sim 280^{\circ} \mathrm{C}$; however, the thermocouple labeled as "Surface" in Figure 7 only reached a maximum temperature of $88-90^{\circ} \mathrm{C}$. Any effects from the heat tape's placement, the hose clamps used to hold the heat tape, the copper foil, or the copper tubing that flowed water, were neglected. For mechanical constraints, the part was constrained in the axial direction along a symmetry plane that intersected the axial center of the pipe. The pipe was also constrained along a symmetry plane perpendicular to the pipe's axis and passing through both the hot and cold sides. The final mechanical constraint ensured that the pipe remained centered about its axis to prevent rigid body motion. The resulting temperature profile and normal strain (along the fiber axis) are shown in Figure 9.

The temperature profile in Figure 9(a) results in a maximum temperature of $\sim 101^{\circ} \mathrm{C}$. However, the main concern is with the temperature gradient between the hot and cold side. Using a temperature probe at the edge of the heat tape in the ANSYS model, similar to where the surface thermocouple was located, a thermal gradient read $30-35^{\circ} \mathrm{C}$ as was observed in Figure 7. The normal strain in the pipe is shown in Figure 9(b), which reports a minimum and maximum strain of -84.93 and $60.57 \mu \mathrm{m}^{\prime} \mathrm{m}^{-1}$, respectively. The maximum strain was observed near the static constraint on the ends of the pipe in the y-axis. Compressive strain was observed on the hot side, whereas the cold side was strain was relatively neutral but slightly positive (tensile). Tensile strain in the cold region was expected since the cold side wants to contract, while the hot side wants to expand, resulting in a transition from compressive strain on the hot side, to tensile strain on the cold side. Interestingly, the maximum tensile strain occurred $\sim 45^{\circ} \mathrm{C}$ away from the hot side. The strain in the fiber, including mechanical strain plus differential thermal strain, was below 60 $\mu \mathrm{m} \cdot \mathrm{m}^{-1}$ (Figure 9(c)), which is similar to the measured values shown in Figure 8(b). 

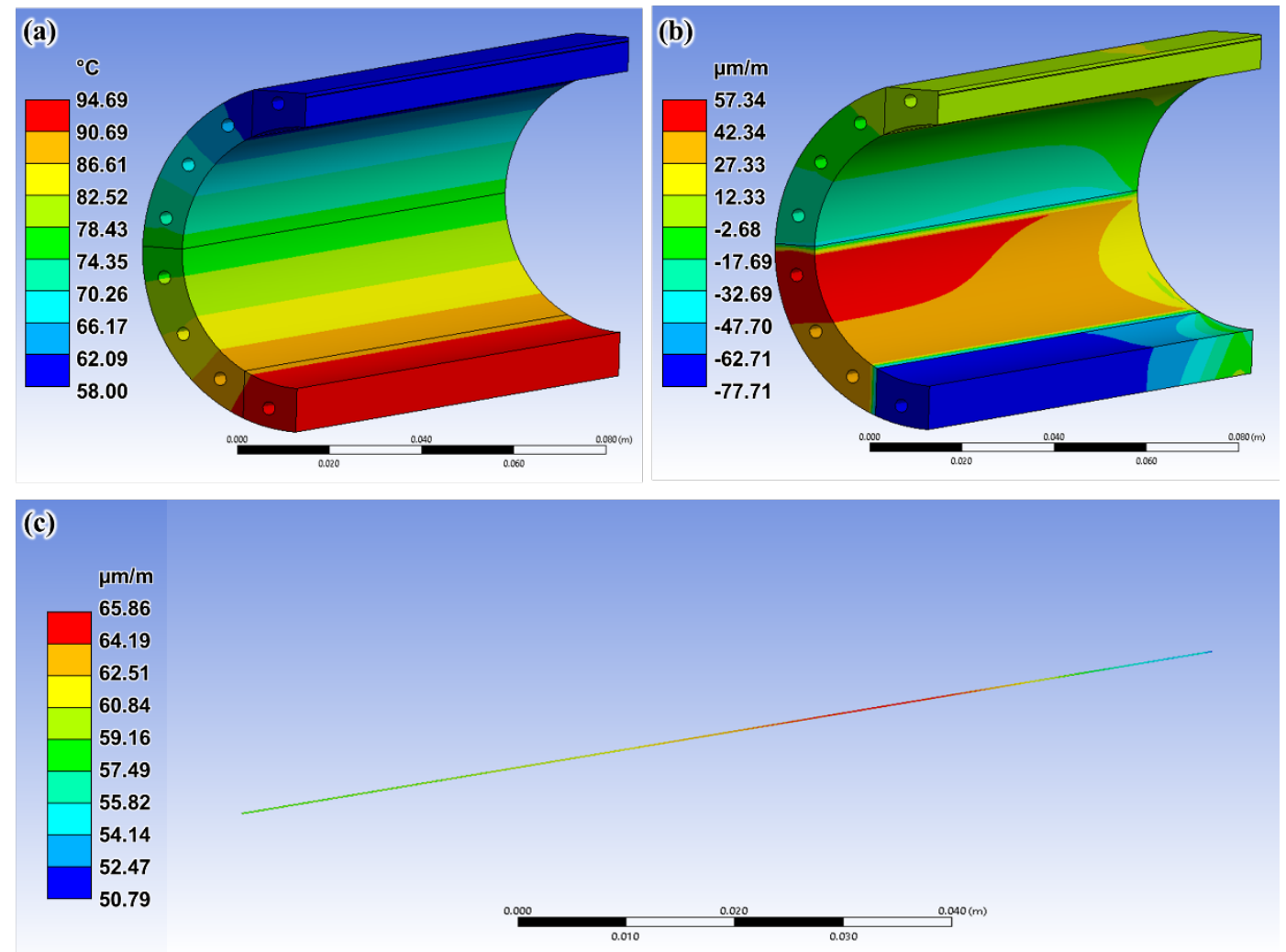

Figure 9. Steady-state thermal analysis of the pipe, showing the (a) temperature profile, (b) normal strain of the pipe, and (c) normal strain in the fiber. The model shows only $1 / 4$ of the pipe due to symmetry. The free end of the pipe is shown on the right side of each image.

\subsection{ACOUSTIC TESTING}

In addition to measuring thermal strain during SPHERE or MAGNET testing, there is interest in using embedded fiber optic sensors for structural health monitoring of microreactor components during operation. For this, one approach is to monitor the resonant frequencies of the structure, which could change if structural flaws (such as cracks) are introduced. This generally requires a sensor that can survive the expected operating conditions while monitoring higher frequency ( $\sim \mathrm{kHz})$ dynamic strains. The fiber optic sensor that was embedded within the pipe specimen was connected to a custom lowcoherence interferometry (LCI) system capable of monitoring higher frequency deflections [40]. In this case, displacement was monitored within a Fabry-Perot cavity (FPC) established between the end of the embedded fiber and the SS304 matrix opposite the fiber end face.

The dynamic deflection of the FPC was monitored during a simple test by manually striking the pipe with a small rubber mallet near the fiber's embedded region. From the LCI system, a spectrograph was created that outputs the frequency of the vibrational waves with its given power density. The first test performed included rapping along the length of the embedded region with multiple 2-3 s pauses in between each set of raps. The second test involved a series of raps on the bench on which the pipe rested, followed by a series of raps on top of the embedded region, with 2-3 s pauses in between each set of raps. As shown in Figure 10(a), there are clear peaks around 5000 and $10000 \mathrm{~Hz}$ when the raps occur on the embedded region of the pipe. Similarly, peaks at 5000 and $10000 \mathrm{~Hz}$ were observed in the second test (Figure 10(b)). Moreover, peaks were only observed when the hammer knocked on the embedded region, 
suggesting that the fiber and FPC are sensitive only to the vibrations of the pipe specimen and not environmental effects.

Since the peaks observed in Figure 10(a) and Figure 10(b) occurred primarily at 5000 and $10000 \mathrm{~Hz}$, a finite element modal analysis performed using ANSYS to estimate the expected resonant frequencies. No constraints were applied to the pipe. The model identified that the pipe specimen had resonant frequencies at 5098 and $10076 \mathrm{~Hz}$, similar to what was measured. The vibrational modes at each resonant frequency are shown in Figure 10(c) for $5098 \mathrm{~Hz}$ and in Figure 10(d) for $10076 \mathrm{~Hz}$, with the total deformation of the part exaggerated for viewing. At a frequency of $5098 \mathrm{~Hz}$, the pipe deforms along the z-axis, expanding/contracting up or downwards. At a frequency of $10076 \mathrm{~Hz}$, the pipe specimen deforms in multiple directions. Future work could use ANSYS or other finite element models to predict resonant frequencies of structural components and determine how they might vary due to flaws such as cracks. The experimental results from this acoustic testing shows that resonant frequencies can be measured, and it may be possible to extend this acoustic monitoring to detect changes in resonant frequencies to identify structural flaws that can be identified with input from the finite element analyses. Future work will further investigate how embedded fibers and FPCs can be used to detect cracks or flaws in relevant microreactor components.
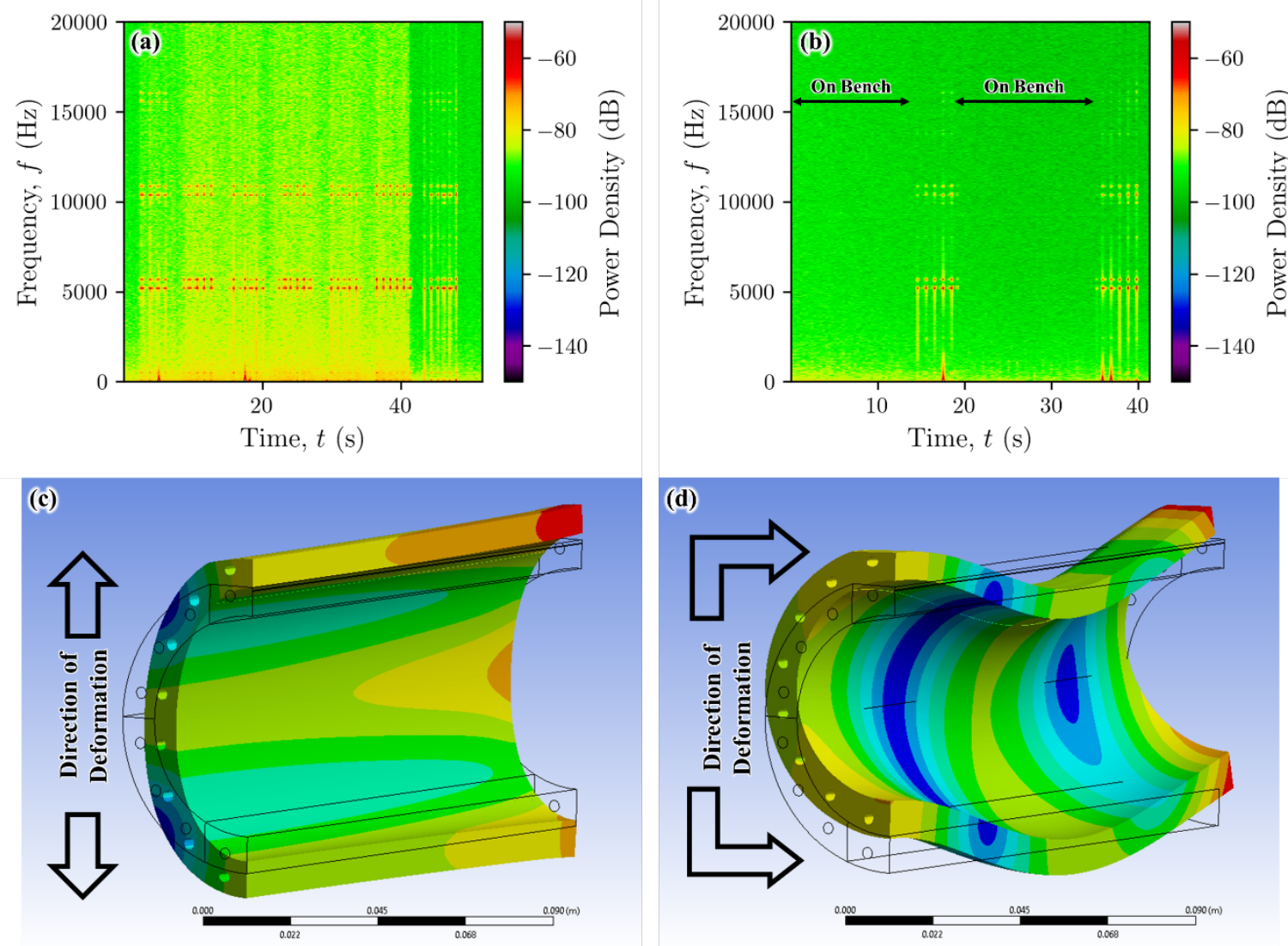

Figure 10. (a, b) Results of acoustic testing after tapping a pipe with a hammer (a) directly on the embedded region of the pipe and (b) on the work bench as well as the pipe. In (b), 10 raps were performed on the work bench away from the pipe, then on the work bench near pipe, and finally directly on the pipe with a few second delay in between each set of raps. Moreover, only the raps directly on the pipe were observed. Intensities in power density were observed near 5,000 and $10,000 \mathrm{~Hz}$. (c, d) ANSYS finite element modeling showing the vibrational modes at two different identified resonant frequencies: (c) 5,098 and (d) 10,076 Hz. 


\subsection{EFFECTS OF UAM PROCESSING ON MICROSTRUCTURE AND MECHANICAL BEHAVIOR}

\subsubsection{Microstructural Characterization}

The previous section highlights the importance of a properly embedded fiber to provide reliable strain measurements. To further understand the effects of the UAM process parameters on the fiber and surrounding SS304 microstructure, additional samples with fibers embedded using UAM were produced for destructive sectioning and microscopy. This study focused on two samples were the focus of this study, one with good bonding and one without any bonding with the SS304 matrix. As shown in Figure 11(a), the fiber with good bonding exhibited little empty space surrounding the fiber compared with the one shown in Figure 11(b), which clearly shows no contact between the fiber and any of the surrounding SS304 material. The fiber shown in Figure 11(a) would likely show significant compressive residual strain and have adequate mechanical coupling to the SS304 matrix to allow for measuring strain. A fiber like the one in Figure 11(b), is a "floating" fiber that would not show significant compressive residual strain and would only give information on temperature. Examples of these differences are shown in Figure 6(a) and Figure 6(b) between the embedded and floating fibers used in the transient thermal testing. The channel width and depth must be clearly controlled to ensure that the fiber is properly bonded to the matrix during UAM.
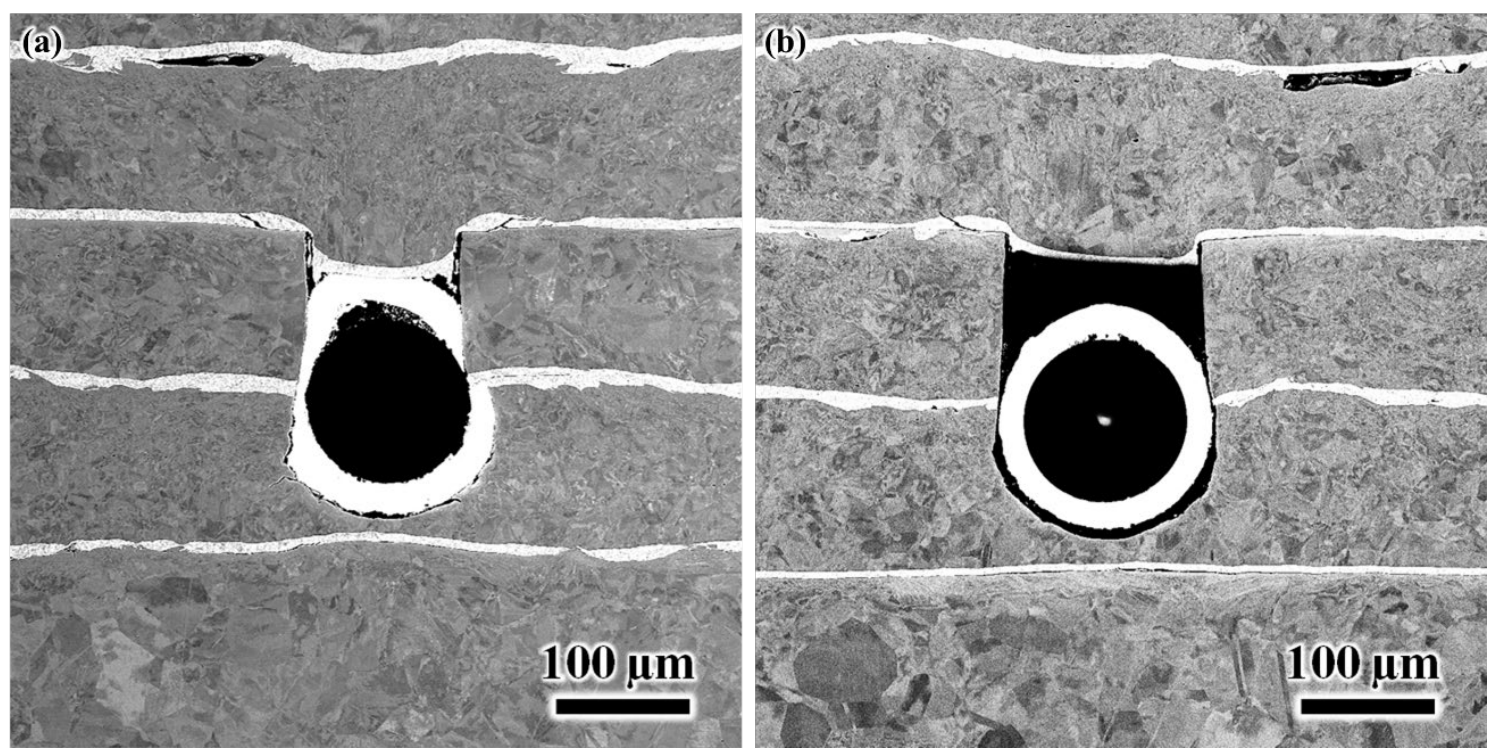

Figure 11. Backscatter electron micrographs of the cross-sections of embedded fibers with (a) successful and (b) unsuccessful bonding of the fiber to matrix.

Even though UAM is a solid-state process that requires no melting, ideal for embedding fragile silica fibers, it relies on the severe plastic deformation of the metal to generate good bonding between the layers and fiber. Therefore, SEM and EBSD analysis was performed to observe the final microstructure after the UAM process and is shown in Figure 12 and Figure 13. As shown in Figure 12(a) and Figure 13(a), the grains in the bulk region of the base plate are fairly equiaxed with a size of approximately $25-35 \mu \mathrm{m}$. Moreover, many annealing twins exist throughout the microstructure of the bulk region. Similarly, the grain structure of the SS304 foils is also equiaxed and filled with annealing twins, as shown in Figure 12(b). This suggests that both the bulk and foils were indeed annealed, giving the "softest" state possible, which is desired for a solid-state process like UAM, to easily deform the microstructure. 
The SS304 foils were electroplated with Ni, creating Ni inter-layers that give the foils a more pliable nature for maximum adhesion during the UAM process. Even though the SS304 was in an annealed state, the Ni inter-layer provides a more deformable surface to assist in the bonding of the SS304 foils. As shown in Figure 13(b), the Ni inter-layers appear to have been epitaxially grown from the SS304 surface grains, which is consistent with the electroplating process. Focusing on the interfaces between the SS304 layers, the grain size decreases significantly as shown in Figure 12(c), Figure 12(d), and Figure 13(b). In particular, the grains in the Ni-interlayer are below $1 \mu \mathrm{m}$. This observation has been made in other UAM investigations on other steel alloys [41, 42]. Moreover, the grain's morphology appears to orient with the "rolling" direction of sonotrode, similar to what would be observed in rolling, drawing, or extrusion processes. In some regions below the Ni interlayer, the grain structure is blurry and not clearly defined. Dehoff and Babu [31] observed a similar region following UAM of Al-alloy 3003, finding that the region was amorphous. However, more detailed, and small-scale analysis such as Transmission Electron Microscopy (TEM) is required to confirm this observation.

Interestingly, the highly deformed region is only present on the bottom of the Ni interlayer and not throughout the entire region. Therefore, the downward force applied from the sonotrode $(7 \mathrm{kN})$ does not deform the entire layer as may be expected. Rather, the deformation is most likely attributed to the ultrasonic scrubbing motion, applying the extent of the force on the very surface of the foil. Moreover, $\mathrm{Ni}$ was electroplated on both sides of the SS304. It cannot be easily distinguished in any of the regions observed that a top and bottom Ni inter layer exists between the two foils. However, since the top of the $\mathrm{Ni}$ interlayer is relatively undeformed, the bottom layer plays the most significant role in the bonding process as it appears to be the region that is most deformed. 

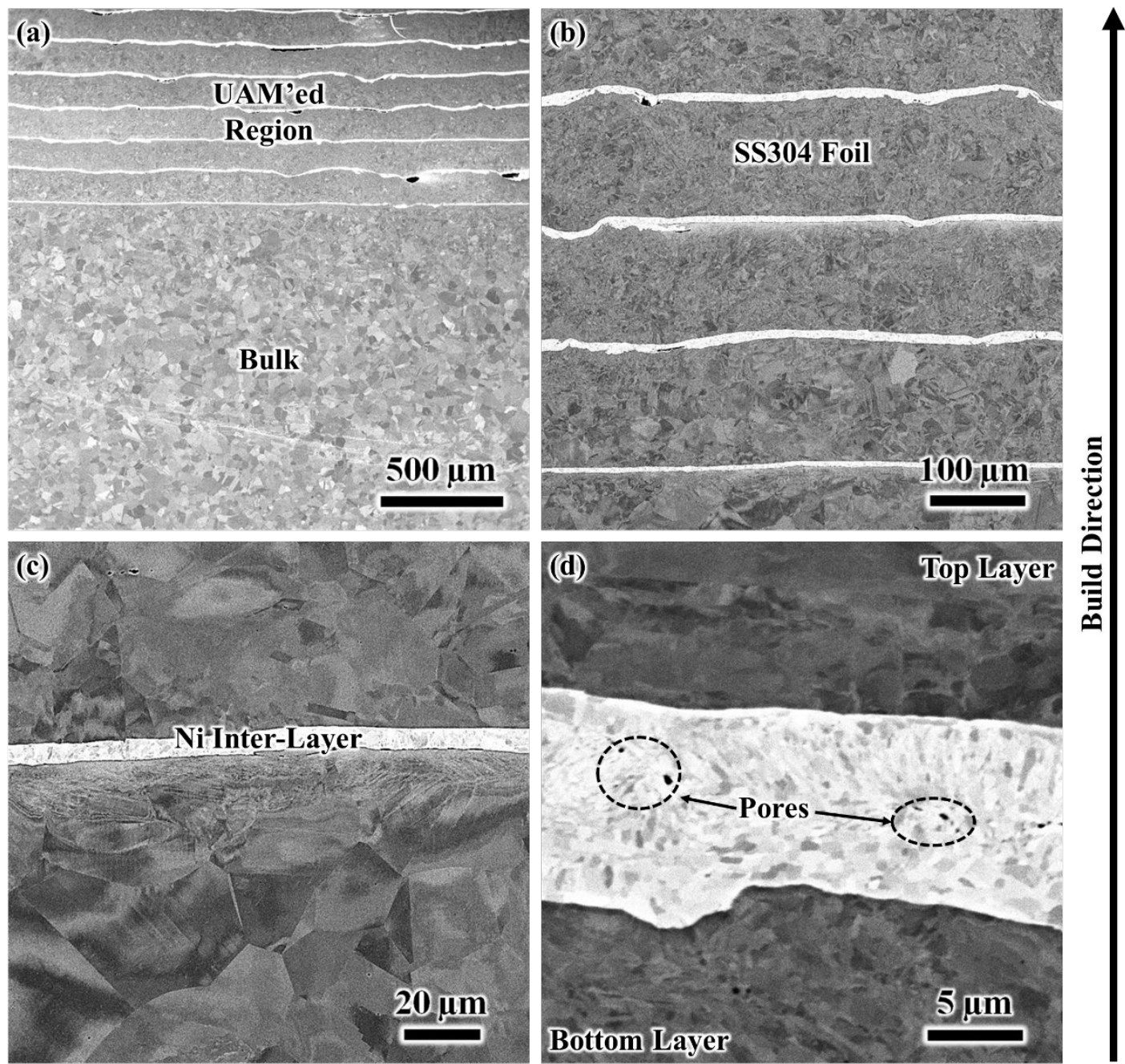

Figure 12. Backscatter electron micrographs of (a) the region between the bulk and the SS304 foils, (b) high magnification of the UAM'ed SS304 foils, and (c, d) high magnification of the grain structure of the Ni interlayer at the interface of the SS304 foils. 

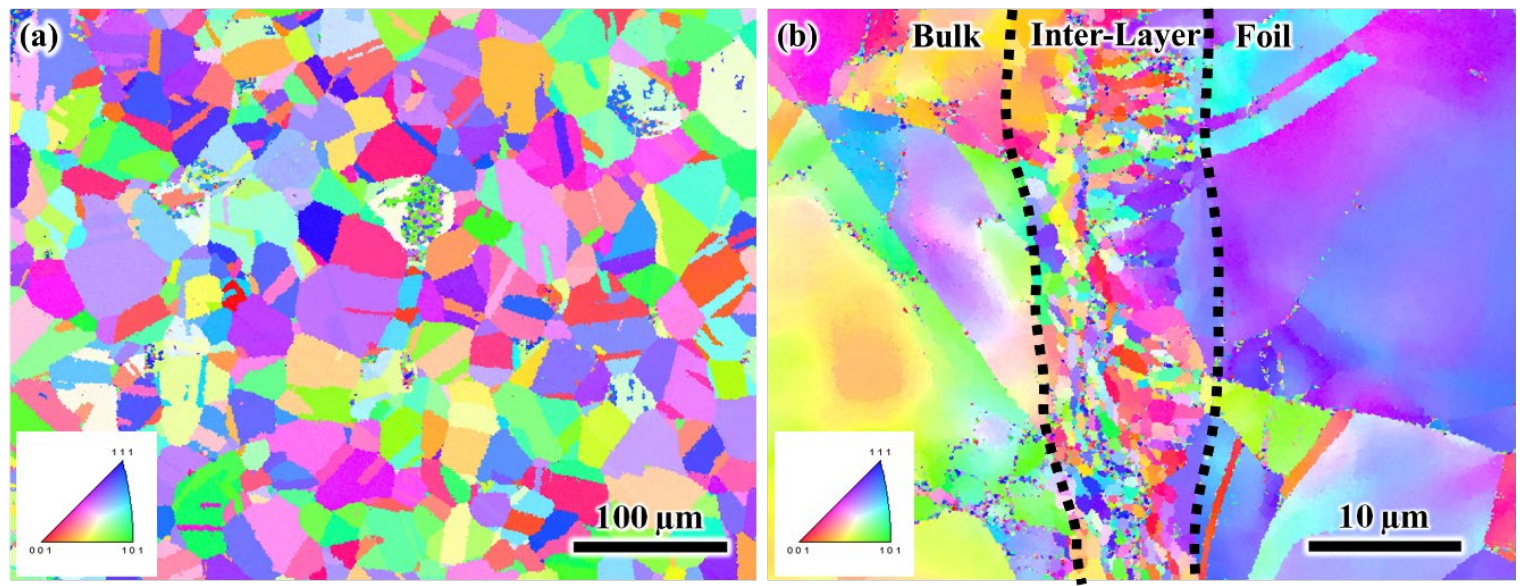

Build Direction

Figure 13. EDSD grain mapping of the (a) bulk region and (b) interface between two UAM foils. The dashed line in (b) indicates the boundary of the Ni inter-layer. The build direction of the samples is given with respect to the bottom length of the images.

\subsubsection{Microhardness}

In the micrographs shown in Figure 12, three regions with different microstructures were identified: in the SS304 layer, at the interface near the Ni inter-layer, and the bulk SS304 on which the SS304 foils were added. Vickers hardness testing was used to evaluate the changes in mechanical behavior at each of the aforementioned regions. Indentation was performed on the sample with good bonding to the SS304 matrix. The results of the Vickers hardness testing are shown in Figure 14, which includes three separate arrays. The array in Figure 14(b) was taken around the embedded fiber while Figure 14(d) and Figure 14(f) were taken away from the embedded region. All arrays include indentation on the SS304 foils and the bulk. The data was segregated based on the position of the indentation, i.e., in the SS304 layer, at the interfaces, or in the bulk regions.

Overall, the highest hardness was observed in the SS304 foils, with the smallest hardness in the bulk regions. The interfaces did not indicate high hardness as may be expected with the small grain size most likely due to defects such as delamination or porosity that were found there. Surprisingly, the highest hardness in the array in (b) was found around the fibers. The indents taken directly on the fiber were removed from the statistical analysis. Therefore, the increase in hardness observed in (a) suggests that the coating of the fiber may have assisted in high plastic deformation, and therefore, lead to an increase hardness around the area. Unfortunately, the differences between the fiber, its coating, and SS304 matrix made it difficult to extract clean grain maps from this region. However, based on the results of the microstructure in Figure 12(d) and Figure 13(b), it is likely that grain structure around the fiber is certainly more refined and possibly similar to the alleged amorphous region under the Ni inter-layer. More in-depth studies are necessary to understand the reason for the mechanical behavior around the embedded fiber. 

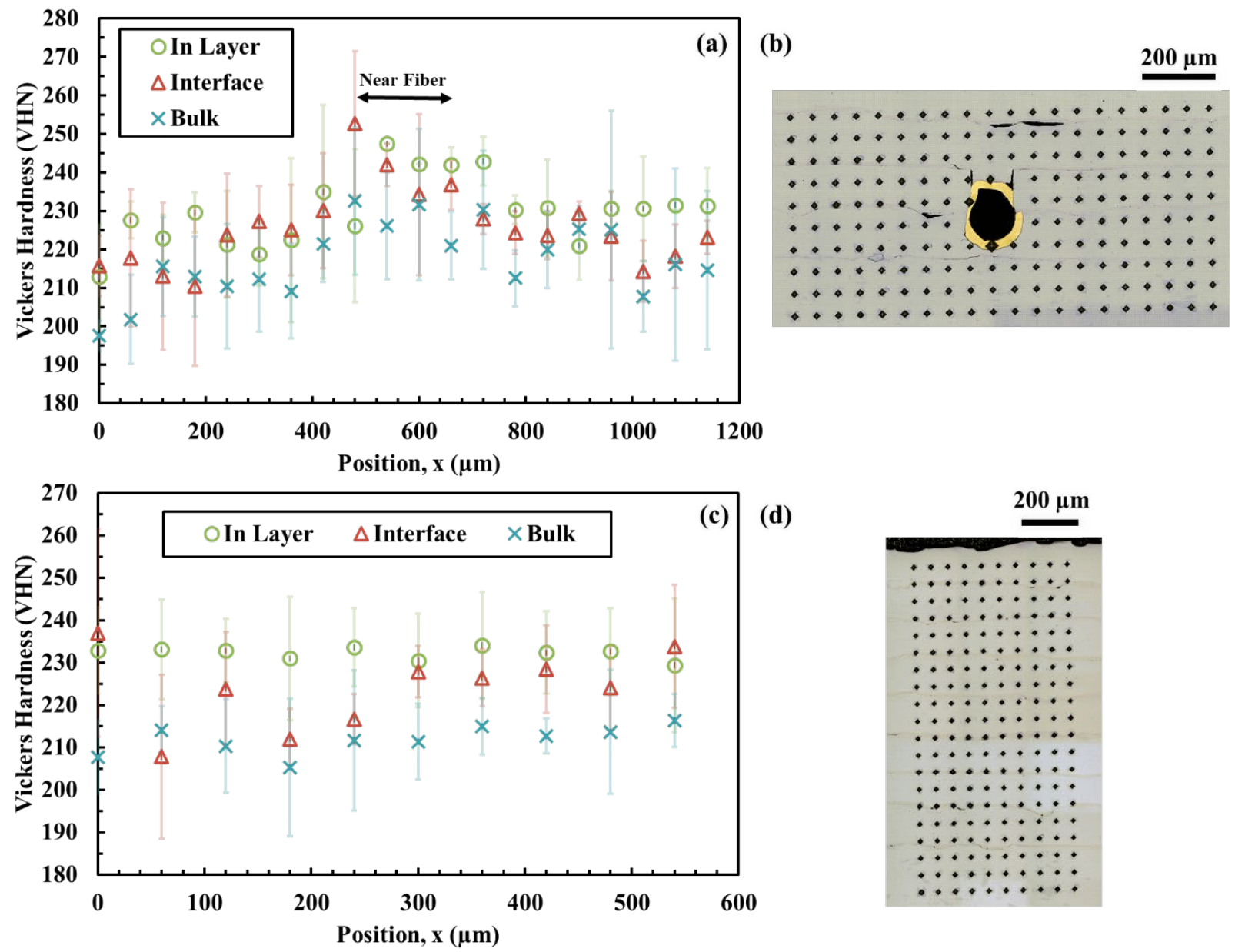

(d)
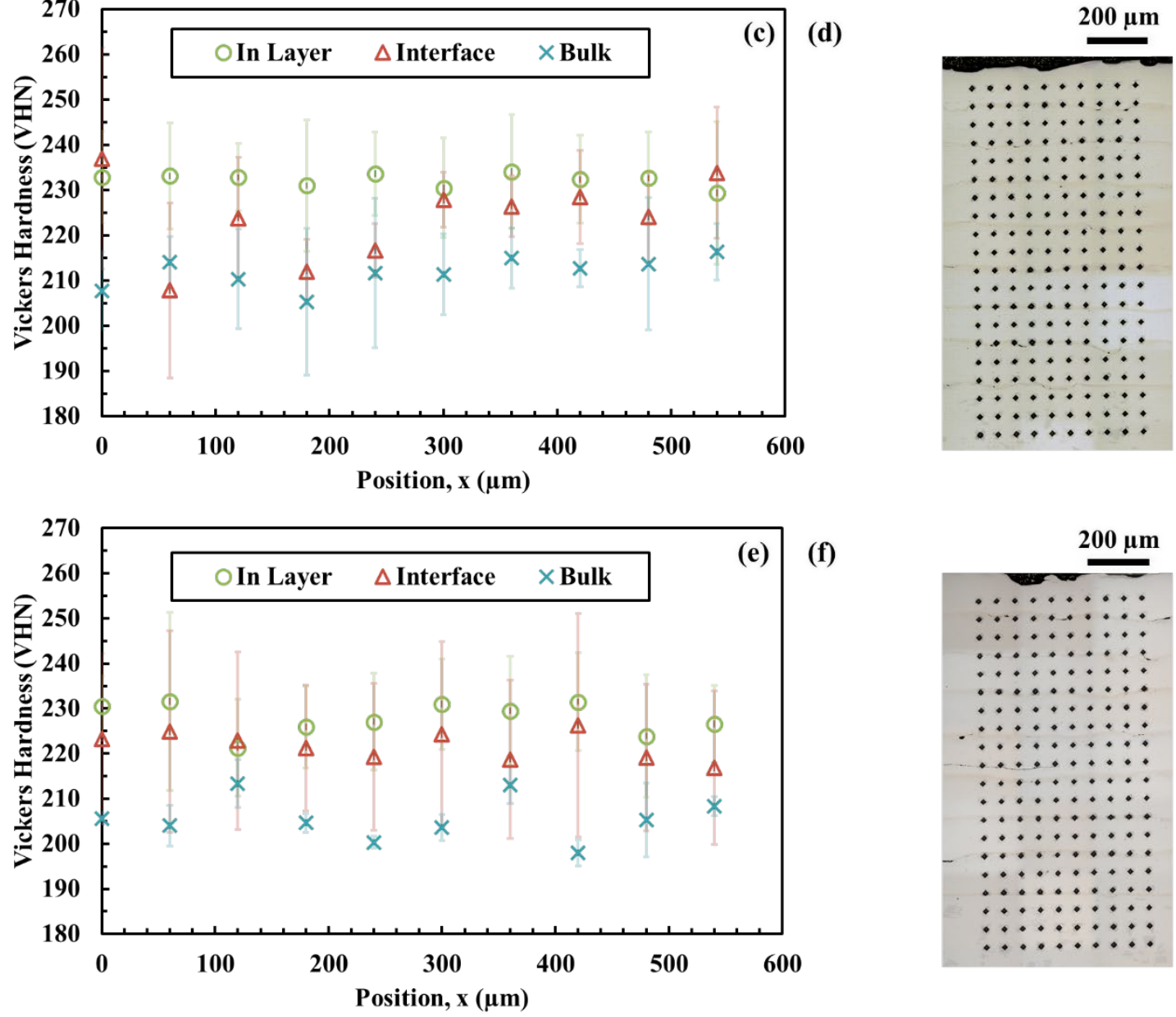

(f)

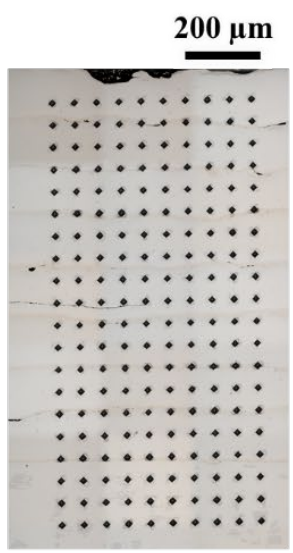

Figure 14. (a, c, e) Vickers hardness data for the areas indicated in (b, d, f), respectively. Indentation was performed on the sample with good bonding to the SS304 matrix. 


\section{NON-NUCLEAR TEST-BED EXPERIMENTS}

\subsection{BACKGROUND ON FACILITIES}

The non-nuclear testbeds being designed and constructed at INL allow for the simulation of representative thermal environments that are expected in microreactors to evaluate the thermal and mechanical response of test articles, moderator materials, and other microreactor systems. The hex block test article described herein and in previous reports $[1,2,24]$ will be one of the first specimens to be tested in these facilities.

The SPHERE facility was designed to test the thermal performance of a single heat pipe inside an $8 \mathrm{ft}$ long quartz tube with a 6 in inner diameter. The quartz tube can be evacuated and backfilled with an inert gas, such as Ar or He. Cartridge heaters $\left(3.8 \mathrm{~W} \cdot \mathrm{cm}^{-2}\right.$ power density) are placed around the heat pipes to heat the working fluid within the heat pipe. The power supply has a maximum power of $20 \mathrm{~kW}$, and the cartridge heaters are rated to a maximum temperature of $750^{\circ} \mathrm{C}$. A $2.5 \mathrm{~kW}$ circulating chiller unit is used to reject heat from the top of the heat pipe by flowing water through a gas gap calorimeter. The gas gap calorimeter consists of an annular shroud that surrounds the heat pipe and passes the chilled water, which is monitored by using precision flow and temperature meters to accurately determine how much heat is being removed from the system. This system can be used to perform steady-state or transient heating of the heat pipe to quantify heat rejection limitations as a function of the working fluid, operating temperature, and heat pipe design. The facility can also be used to drive thermal gradients through the test articles that contain the cartridge heaters and the heat pipe to evaluate heat transfer within the test articles and their thermomechanical response.

The MAGNET facility is a larger testbed $(5 \times 5 \times 10 \mathrm{ft})$ designed to test a wide range of relevant microreactor components and systems. Initial testing at MAGNET is focused on developing heat pipebased microreactors, but the facility was designed to house a wide range of samples and test articles that span many different classes of microreactors. Similar to SPHERE, the chamber atmosphere can be evacuated and backfilled with Ar or He inert gases, and the maximum testing temperature is generally limited by the maximum rated temperature of the cartridge heaters. However, MAGNET uses a $250 \mathrm{~kW}$ electric power supply to energize many cartridge heaters. This allows larger components or heat transfer systems to be tested to evaluate integrated system performance. The system will be gas cooled with air or an inert gas, such as $\mathrm{N}_{2}$ or $\mathrm{He}$, and will have liquid-cooled chamber walls. The facility will allow the central temperature of the cartridge heaters, the test chamber, and any surface readings of the test articles to be monitored.

For both the MAGENT and SPHERE facilities, embedded sensors give a more accurate measurement of the internal temperature and/or strain within the test articles. This provides a more complete picture of heat transfer and potential mechanical failure modes within the test articles.

\subsection{TESTING PLAN FOR FY22}

Testing in FY22 will be performed with test articles that were fabricated in FY20 and FY21. Although there is interest in performing more exhaustive testing, budget constraints in FY20 and FY21 limited the development of the sensor embedding process so that only one SPHERE test article - the seven-hole hex block shown in Figure 3 was fabricated with embedded sensors. Because the nondestructive evaluation of the hex block (Figure 5) showed similar compressive residual strain and signal attenuation in the embedded fiber-optic sensors compared with the pipe specimen tested in this report, the embedded sensors in the hex block are expected to perform similarly to the sensors tested in the pipe specimen. The goals of this initial testing are to perform simple start-up, shutdown, and monitoring during transient operations. Thermocouples, thermal imaging with digital image correlation (DIC), and strain gauges will monitor heating from cartridge heaters. The original timeline for various tests to be performed at 
MAGENT and SPHERE for the end of FY21 through FY22 are reported in Table 1. The tests that could include embedded sensors are highlighted in gray.

Table 1: Time line for the proposed testing of relevant microreactor test articles at the MAGNET and SPHERE facilities [2,3]. The tests that could include test articles with embedded sensors are highlighted in gray.

\begin{tabular}{|c|c|c|}
\hline Facility & Task to be performed & $\begin{array}{l}\text { Expected time } \\
\text { frame }\end{array}$ \\
\hline \multirow{8}{*}{ MAGNET } & Single SS heat pipe test article & $\begin{array}{l}\text { Spring-summer } \\
2021\end{array}$ \\
\hline & $\begin{array}{l}\text { Determine the effect of gaps between heat pipes starting with the seven-hole } \\
\text { hex block }\end{array}$ & Summer-fall 2021 \\
\hline & $\begin{array}{c}\text { Operate the heat exchanger setup with low-pressure air coolant and high- } \\
\text { pressure } \mathrm{N}_{2} \text { coolant to determine heat transfer and thermal stress } \\
\text { performance }\end{array}$ & \multirow[t]{2}{*}{ Fall 2021} \\
\hline & Test condenser and document the heat transfer as a function of length & \\
\hline & Test the 37-heat pipe article and heat exchanger & \multirow{4}{*}{$\begin{array}{l}\text { Spring-summer } \\
\quad 2022\end{array}$} \\
\hline & Characterize the heat transfer from the pipes to the heat exchanger & \\
\hline & Analyze any potential failures of the heat pipe & \\
\hline & Measure the strain via the DIC method & \\
\hline \multirow{10}{*}{ SPHERE } & $\begin{array}{c}\text { Perform preliminary tests of cartridge heaters, power control, water cooling, } \\
\text { calorimetry, and temperature measuring }\end{array}$ & Completed \\
\hline & Perform heat pipe performance tests with different orientations & $\begin{array}{l}\text { Spring-summer } \\
\quad 2021\end{array}$ \\
\hline & Determine the integrity of welds on SS structure & \multirow{4}{*}{ Summer-fall 2021} \\
\hline & Evaluate the temperature sensing capabilities with one heat pipe & \\
\hline & Evaluate the creep and fatigue behavior of structural materials & \\
\hline & Test data accumulation for fundamental understanding and validation & \\
\hline & Perform heat pipe failure testing & \multirow{4}{*}{ Fall-winter 2021} \\
\hline & Perform transient heat pipe performance testing & \\
\hline & Apply DIC imaging to measure strain & \\
\hline & $\begin{array}{l}\text { Use system measurements to determine the integrity of structure and } \\
\text { welds/bonds of SS structure at high temperature }\end{array}$ & \\
\hline
\end{tabular}

\section{SUMMARY}

This report discusses the applicability and characterization of embedded sensors in relevant microreactor components. Both thermocouples and spatially distributed fiber optic strain and temperature sensors were embedded within SS pipes and a more complex hex block test article relevant to heat pipe-based microreactors. The sensors were embedded via the UAM process, which includes machining cavities for the sensors to lay and then ultrasonically welding metal foils over the top. Low signal attenuation was observed after the embedding process, and the residual strain in the fiber was used as a nondestructive metric for determining whether the fiber was correctly embedded. During post-embedding transient thermal testing, the strain measured by the embedded fibers generally followed the predicted thermal strain calculated by using the measured temperatures and known thermal expansion coefficients of the 
silica fiber and SS304 matrix. The same pipe specimen was used to demonstrate acoustic monitoring, which identified resonant frequencies that matched those from modal finite element analyses. These results are encouraging for the potential use of embedded fiber optic sensors for structural health monitoring of microreactor components. To further understand the mechanisms responsible for the sensor bonding during UAM, additional microstructural characterization was performed. The severe plastic deformation of the UAM process resulted in significantly refining the grain structure at the layer-fiber interface, which increased the overall hardness in these regions. Theses core pipes and hex blocks are to be tested at INL's non-nuclear testbeds SPHERE and MAGNET. The results observed from these thermal tests indicate that accurate strain and temperature can be measured via the embedded sensors, which can also help calibrate the temperature data measured from the instruments at the SPHERE and MAGNET facilities.

\section{REFERENCES}

[1] J. Yoo, Qin, Sunming, Song, Minseop, Hartvigsen, Jeremy L., Sellers, Zackary D., Morton, Terry J., Sabharwall, Piyush, Hansel, Joshua, Ibarra, Lander, Feng, Bo, Petrie, Christian M., Modeling and Analysis Support for High Temperature Single Heat Pipe Experiment: Current Status and Plan, Idaho National Laboratory, Idaho Falls, Idaho, 2021, pp. 1-46.

[2] P. Sabharwall, Trellue, Holly, Hartvigsen, Jeremy, Morton, Terry, Guillen, Donna, Arafat, Yasir, Cutler, Theresa, Luther, Erik, Reid, Robert, Taylor, Chase, Unruh, Troy, Petrie, Chris, Mascarenas, David, Meyerhoffer, Peter, Gehin, Jackson, John, DOE Microreactor Program: Summary of Experimental Capabilities Development and Activities, Idaho National Laboratory, Idaho Falls, Idaho, 2021, pp. 1-47. [3] H.R. Trellue, J. O'Brien, R.S. Reid, D. Guillen, P. Sabharwall, Microreactor Agile Nonnuclear Experimental Testbed Test Plan, Los Alamos National Lab.(LANL), Los Alamos, NM (United States), 2020.

[4] H. Rows, LV. The vapour pressures of the alkali metals, The London, Edinburgh, and Dublin Philosophical Magazine and Journal of Science 3(15) (1927) 534-546.

[5] P.R. Mcclure, D.I. Poston, V.R. Dasari, R.S. Reid, Design of megawatt power level heat pipe reactors, Los Alamos National Lab.(LANL), Los Alamos, NM (United States), 2015.

[6] P.R. Mcclure, D.I. Poston, V.R. Dasari, R.S. Reid, Design of megawatt power level heat pipe reactors, Los Alamos National Laboratory, Los Alamos, NM, 2015.

[7] K.O. Hill, G. Meltz, Fiber Bragg grating technology fundamentals and overview, J. Lightwave Technol. 15(8) (1997) 1263-1276.

[8] S.T. Kreger, D.K. Gifford, M.E. Froggatt, B.J. Soller, M.S. Wolfe, High resolution distributed strain or temperature measurements in single-and multi-mode fiber using swept-wavelength interferometry, Optical Fiber Sensors, Optical Society of America, 2006, p. ThE42.

[9] C.M. Petrie, D.P. Hawn, W. Windl, T.E. Blue, Reactor radiation-induced attenuation in fused silica optical fibers heated up to 1000 C, Journal of Non-Crystalline Solids 409 (2015) 88-94.

[10] C.M. Petrie, B. Wilson, T.E. Blue, In Situ Gamma Radiation-Induced Attenuation in Sapphire Optical Fibers Heated to $1000^{\circ}$ C, J. Am. Ceram. Soc. 97(10) (2014) 3150-3156.

[11] D.P. Hawn, C.M. Petrie, T.E. Blue, W. Windl, In-situ gamma radiation induced attenuation in silica optical fibers heated up to 600 C, Journal of Non-Crystalline Solids 379 (2013) 192-200.

[12] C.M. Petrie, N. Sridharan, In situ measurement of phase transformations and residual stress evolution during welding using spatially distributed fiber-optic strain sensors, Meas. Sci. Technol. 31(12) (2020) 125602.

[13] C.M. Petrie, S. Niyanth, C. Frederick, T. Mcfalls, S. Babu, A. Hehr, M. Norfolk, J. Sheridan, Embedded Fiber-Optic Sensors for In-Pile Applications, Oak Ridge National Lab.(ORNL), Oak Ridge, TN (United States), 2019.

[14] C.M. Petrie, A. Schrell, D. Leonard, B.C. Jolly, Demonstration of Embedded Sensors in Ceramic Structures, Oak Ridge National Lab.(ORNL), Oak Ridge, TN (United States), 2020. 
[15] C.M. Petrie, N. Sridharan, A. Hehr, M. Norfolk, J. Sheridan, High-temperature strain monitoring of stainless steel using fiber optics embedded in ultrasonically consolidated nickel layers*, Smart Mater. Struct. 28(8) (2019) 085041.

[16] C.M. Petrie, N. Sridharan, M. Subramanian, A. Hehr, M. Norfolk, J. Sheridan, Embedded metallized optical fibers for high temperature applications, Smart Mater. Struct. 28(5) (2019) 055012.

[17] S. Wang, K. Lasn, C.W. Elverum, D. Wan, A. Echtermeyer, Novel in-situ residual strain measurements in additive manufacturing specimens by using the Optical Backscatter Reflectometry, Addit. Manuf. 32 (2020) 101040.

[18] C. Hensley, K. Sisco, S. Beauchamp, A. Godfrey, H. Rezayat, T. McFalls, D. Galicki, F. List III, K. Carver, C. Stover, Qualification Pathways for Additively Manufactured Components for Nuclear Applications, J. Nucl. Mater. (2021) 152846.

[19] X. Hu, T.G. Lach, K.A. Terrani, Deuterium permeation and retention in 316L Stainless Steel Manufactured by Laser Powder Bed Fusion, J. Nucl. Mater. 548 (2021) 152871.

[20] W.J. Sames, F. List, S. Pannala, R.R. Dehoff, S.S. Babu, The metallurgy and processing science of metal additive manufacturing, Int. Mater. Rev. 61(5) (2016) 315-360.

[21] H. Hyer, R. Newell, D. Matejczyk, S. Hsie, M. Anthony, L. Zhou, C. Kammerer, Y. Sohn,

Microstructural Development in As Built and Heat Treated IN625 Component Additively Manufactured by Laser Powder Bed Fusion, Journal of Phase Equilibria and Diffusion 42(1) (2021) 14-27.

[22] D. Havermann, J. Mathew, W.N. MacPherson, R.R. Maier, D.P. Hand, Temperature and strain measurements with fiber Bragg gratings embedded in stainless steel 316, J. Lightwave Technol. 33(12) (2014) 2474-2479.

[23] R. Zou, X. Liang, Q. Chen, M. Wang, M.A. Zaghloul, H. Lan, M.P. Buric, P.R. Ohodnicki, B. Chorpening, A.C. To, A Digital Twin Approach to Study Additive Manufacturing Processing Using Embedded Optical Fiber Sensors and Numerical Modeling, J. Lightwave Technol. 38(22) (2020) 64026411.

[24] C.M. Petrie, N.D.B. Ezell, Demonstrate embedding of sensors in a relevant microreactor component, Oak Ridge National Lab.(ORNL), Oak Ridge, TN (United States), 2020.

[25] H. Hyer, L. Zhou, Q.Y. Liu, D.Z. Wu, S.T. Song, Y.L. Bai, B. McWilliams, K. Cho, Y. Sohn, High strength WE43 microlattice structures additively manufactured by laser powder bed fusion, Materialia 16 (2021) 101067.

[26] H. Hyer, L. Zhou, A. Mehta, S. Park, T. Huynh, S.T. Song, Y.L. Bai, K. Cho, B. McWilliams, Y. Sohn, Composition-dependent solidification cracking of aluminum-silicon alloys during laser powder bed fusion, Acta Mater. 208 (2021) 116698.

[27] H. Hyer, L. Zhou, S. Park, G. Gottsfritz, G. Benson, B. Tolentino, B. McWilliams, K. Cho, Y. Sohn, Understanding the Laser Powder Bed Fusion of AlSi10Mg Alloy, Metallography Microstructure and Analysis 9(4) (2020) 484-502.

[28] Y. Polsky, P. Groth, B. Warmack, A. Melin, R. Kisner, Embedded Sensor Development in Metallic Structures for the Transformational Challenge Reactor, Oak Ridge National Laboratory, Oak Ridge, 2019. [29] A. Hehr, M. Norfolk, A comprehensive review of ultrasonic additive manufacturing, Rapid Prototyp. J. (2019).

[30] A. Hehr, M. Norfolk, J. Wenning, J. Sheridan, P. Leser, P. Leser, J.A. Newman, Integrating Fiber Optic Strain Sensors into Metal Using Ultrasonic Additive Manufacturing, JOM 70(3) (2018) 315-320.

[31] R. Dehoff, S. Babu, Characterization of interfacial microstructures in 3003 aluminum alloy blocks fabricated by ultrasonic additive manufacturing, Acta Mater. 58(13) (2010) 4305-4315.

[32] H.T. Fujii, S. Shimizu, Y.S. Sato, H. Kokawa, High-strain-rate deformation in ultrasonic additive manufacturing, Scripta Mater. 135 (2017) 125-129.

[33] E. Cakmak, M.N. Gussev, N. Sridharan, M.H. Seren, K. An, H. Wang, K.A. Terrani, Micromechanical and microstructure analysis of strain-induced phenomena in ultrasonic additivelymanufactured Al-6061 alloy, Mater. Sci. Eng. A 770 (2020) 138533.

[34] M. Pagan, C. Petrie, D. Leonard, N. Sridharan, S. Zinkle, S.S. Babu, Interdiffusion of Elements During Ultrasonic Additive Manufacturing, Metall. Mater. Trans. A (2021). 
[35] N. Sridharan, P. Wolcott, M. Dapino, S. Babu, Microstructure and texture evolution in aluminum and commercially pure titanium dissimilar welds fabricated using ultrasonic additive manufacturing, Scripta Mater. 117 (2016) 1-5.

[36] P. Wolcott, N. Sridharan, S. Babu, A. Miriyev, N. Frage, M. Dapino, Characterisation of Al-Ti dissimilar material joints fabricated using ultrasonic additive manufacturing, Sci. Technol. Weld. Joining 21(2) (2016) 114-123.

[37] A. Hehr, J. Wenning, K. Terrani, S.S. Babu, M. Norfolk, Five-axis ultrasonic additive manufacturing for nuclear component manufacture, JOM 69(3) (2017) 485-490.

[38] D.C. Sweeney, A.M. Schrell, C.M. Petrie, An Adaptive Reference Scheme to Extend the Functional Range of Optical Backscatter Reflectometry in Extreme Environments, IEEE Sens. J. 21(1) (2021) 498509.

[39] B. Soller, M. Wolfe, M. Froggatt, Polarization resolved measurement of Rayleigh backscatter in fiber-optic components, National Fiber Optic Engineers Conference, Optical Society of America, 2005, p. NWD3.

[40] D.C. Sweeney, A.M. Schrell, Y. Liu, C.M. Petrie, Metal-embedded fiber optic sensor packaging and signal demodulation scheme towards high-frequency dynamic measurements in harsh environments, Sensors and Actuators A: Physical 312 (2020) 112075.

[41] T. Han, C.-H. Kuo, N. Sridharan, L.M. Headings, S.S. Babu, M.J. Dapino, Effect of preheat temperature and post-process treatment on the microstructure and mechanical properties of stainless steel 410 made via ultrasonic additive manufacturing, Mater. Sci. Eng. A 769 (2020) 138457.

[42] A. Levy, A. Miriyev, N. Sridharan, T. Han, E. Tuval, S.S. Babu, M.J. Dapino, N. Frage, Ultrasonic additive manufacturing of steel: method, post-processing treatments and properties, J. Mater. Process.

Technol. 256 (2018) 183-189. 